\title{
User Satisfaction with E-Government Services: An Experimental Study on Public Administrations in the Lebanese Republic
}

\author{
Nabila Abass \\ Faculty Of Economic and Business Administration \\ Al Jinan University- Lebanon \\ prof.nabilabass@gmail.com
}

\author{
Alissar Ali Tahan \\ Faculty Of Economic and Business Administration \\ Al Jinan University- Lebanon \\ management@khadraframes.com
}

\begin{abstract}
:
This study aims to identify the extent of user satisfaction in Lebanon with the services provided electronically in public administrations, after building a comprehensive framework on e-government, and this framing is the starting point towards examining the extent of application of information and communication technology tools in public administrations, and their relationship to user satisfaction. Data is collected from secondary sources through books, references, journals, periodicals, and websites, and from primary sources through a sample of users of government services for each of the following ministries (Ministry of Finance, Ministry of Labor, Ministry of Energy and Water, Ministry of Public Health, Ministry of Communications, Ministry of Trade and Economy) in the Lebanese Republic, it reached (384) individuals using the simple random sample, and (324) are recovered. The researcher followed the descriptive and analytical method in analyzing the data to arrive at the results, using the SPSS statistical analysis program. The study found a set of results, including:

1. The existence of a statistically significant relationship between the acquisition of technological means and the users' satisfaction with the services in the Lebanese electronic interests.

2. The existence of a statistically significant relationship between the use of software and networks and the users' satisfaction with the services in the Lebanese electronic interests.

3. The existence of a statistically significant relationship between the quality of information and the users' satisfaction with the services in the Lebanese e-services.
\end{abstract}

Keywords: e-government, user satisfaction, e-services. 


\section{مدى رضا المستخدمين عن الخدماث الحكومية الإلكترونية:}

\section{(دراسة تجريسية على الإدارات العامة في الجمهورية اللبنانية)}

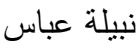

كلية العلوم الاقتصادية وإدارة الأعمال

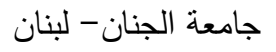

prof.nabilabass@gmail.com

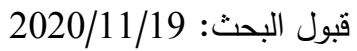

أليسار علي طحان

كلية العلوم الاقتصادية وإدارة الأعمال

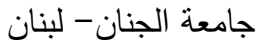

management@khadraframes.com

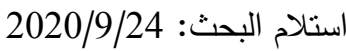

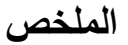

تهدف هذه الدراسة إلى التعرف على مدى رضا المستخدمين في لبنان عن الخدمات المقدمة إلكترونياً في الإدارات العامة، بعد بناء تأطير شامل عن الحكومة الإلكترونية، ويكون هذا التأطير نقطة الانطلاق نحو بحث مدى تطبيق أدوات تكنولوجيا المعلومات والاتصالات في الإدارات

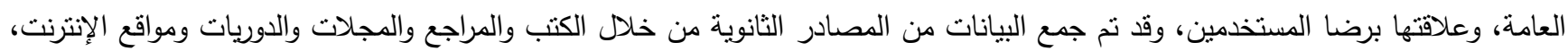
ومن المصادر الأولية من خلال عينة من المستخدمين للخدمات الحكومية لكل من الوزارات التالية (وزارة المالية، وزارة العمل، وزارة الطاقة والمياه،

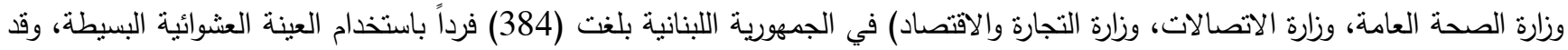
تم استرداد (324)منها ، وقامت الباحثة باستخدام المنهج الوصفي التحليلي في تحليل البيانات للوصول إلى النتائج مستعينةً ببرنامج التحليل الإحصائي SPSS. وقد توصلت الدراسة إلى مجموعة من النتائج من بينها:

1-وجود علاقة ذات دلالة إحصائية بين الحصول على الوسائل التكنولوجية ورضا المستخدمين عن الخدمات في المصالح الإلكترونية

2-وجود علاقة ذات دلالة إحصائية بين استخدام البرمجيات والثبكات ورضا المستخدمين عن الخدمات في المصالح الإلكترونية اللبنانية.

3-وجود علاقة ذات دلالة إحصائية بين جودة المعلومات ورضا المستخدمين عن الخدمات في المصالح الإككرونية اللبنانية.

الكلمات المفتاحية: الحكومة الإككترونية، رضا المستخدمين، الخدمات الإلكترونية.

وتعتبر الحكومة الإككترونية نمطاً جديداً ومنطوراً للإدارة تؤدي

المقدمة

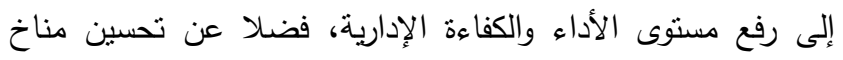

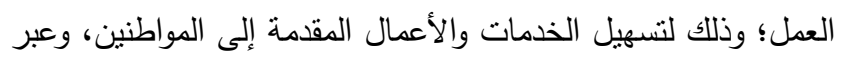
هذا النمط الجديد من العمل؛ سيتمكن المواطن الطالب للخدمة من إنجاز كافة المعاملات بواسطة الوسائل الالكترونية.

وتعود أهمية الحكومة الإككترونية إلى الصعوبات التي يلاقيها

المواطن وأصحاب العمل في التعامل مع الجهات الحكومية، وبالإضافة إلى رغبة الحكومة في استغلال ثورة الإنترنت والمعلومات

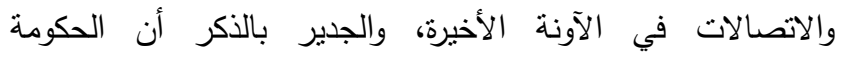

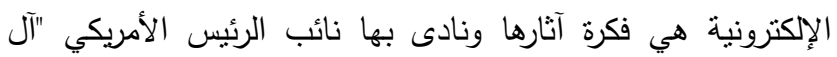

يعد موضوع الحكومة الإلكترونية من المواضيع الحديثة المعروضة على الساحة الإقليمية والدولية، والتي استقطبت اهنماماً كبيراً؛ بوصفها إحدى الوسائل الفاعلة للتكيف والإفادة من معطيات

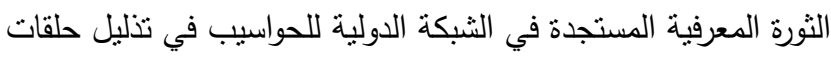

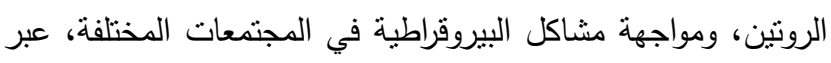
الانتقال من نقديم الخدمات العامة والمعاملات الخاصة من شكلها الروتيني إلى الثكل الإلكتروني عبر الإنترنت. 
• ما هو أثز جودة الخدمات الإلكترونية على رضا المستخدمين والفائدة المدركة من استخدامها؟

\section{ثانياً: فروض الاراسة}

ولإجابة عن الإشكالية المطروحة والأسئلة الفرعية؛ تم بناء

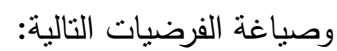

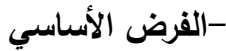

( لا توجد علاقة ذات دلالة إحصائية بين تطبيق الحكومة الإكترونية والفائدة المدركة، ورضا المستخدمين عن الخدمات الإلكترونية بالمصالح الحكومية اللبنانية.

) توجد علاقة ذات دلالة إحصائية بين تطبيق الحكومة الإلكترونية والفائدة المدركة، ورضا المستخدمين عن الخدمات الإلكترونية بالمصالح الحكومية اللبنانية.

وينبثق عن هذا الفرض الفروض الفرعية التالية الفرض الرئيسي الأول

( لا توجد علاقة ذات دلالة إحصائية بين الحكومة الإكترونية (حصول المستخدمين على الوسائل التكنولوجية، استخدام البرمجيات والثبكات) والفائدة المدركة، ورضا المستخدمين عن الخدمات الإلكترونية بالمصالح الحكومية اللبنانية.

(H1 (حصول المستخدمين على الوسائل التكنولوجية، استخدام البرمجيات والثبكات) والفائدة المدركة، ورضا المستخدمين عن الخدمات الإلكترونية بالمصالح الحكومية اللبنانية.

وينبثق عن هذا الفرض الفروض الفرعية التالية

$$
\text { أ) الفرض الفرعي الأول }
$$

( لا توجد علاقة ذات دلالة إحصائية بين حصول المستخدمين

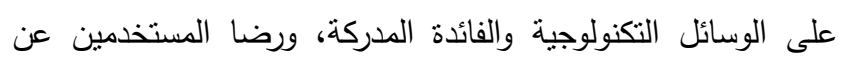
الخدمات الإككترونية بالمصالح الحكومية اللبنانية.

(H على الوسائل التكنولوجية والفائدة المدركة، ورضا المستخدمين عن الخدمات الإلكترونية بالمصالح الحكومية اللبنانية.

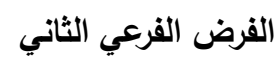

( $\mathrm{H}_{0}$ والثبكات والفائدة المدركة، ورضا المستخدمين عن الخدمات الإلكترونية بالمصالح الحكومية اللبنانية.
جور" ضمن تصور لديه لربط المواطن بمختلف أجهزة الحكومة للحصول على الخدمات الحكومية بأنواعها بشكل آلي ومؤتمت، إضافة إلى إنجاز الحكومة ذاتها مختلف أنشطتها باعتماد شبكات الاتصال والمعلومات؛ لخفض التكلفة وتحسين الأداء وسرعة الإنجاز وفعالية التنفيذ.

والسؤال المطروح من خضم هذه المتغيرات والمزايا المترتبة على تحول الحكومة إلى النظام الالكتروني، هو (إلى أي مدى يمكن أن يؤثر تطبيق الحكومة الاككترونية على رضا المستخدمين؟). أولاً: إشكالية الاراسة وأسئلتها إن القطاع الحكومي في (لبنان) يتصف بالبيروقراطية والروتين؛ من حيث إنجازُ الأعمال التي تعد إحدى أسباب فساد وتخلف الإدارة العامة، وأحيانا تعقيد الإجراءات دون مبرر، الأمر الذي يعني تعطيل العمل ووضع العراقيل، وهو ما لا يتتاسب مع متطلبات المرحلة التي يعيشها العالم في الوقت الحالي؛ إذ تعتمد هذه المرحلة على سرعة أداء وإنجاز الأعمال في وقت قياسي.

لذا أصبحت الحاجة ملحةً إلى تحديث الأجهزة الحكومية بشكل بنعكس ليس على الأفراد فقط بل على كل سلطات الدولة؛ بشكل صورة انجاز الخدمات بصورة أكثر فاعلية ، فتطبيق مشروع الحكومة الإكترونية في حياتتا اليومية يعتبر تحولاً كبيراً عن كل ما هو مألوف لدى جمهور المستفيدين من خدمات الحكومة التقليدية، وتدور إثكالية هذه الدراسة في إطار تأثثر اتباع النظام الرقمي في الإدارة الحكومية، وتأثير ذلك على منظومة العمل داخل الحكومة بجوانبها المختلفة بالصورة التي تسمى الحكومة الإكترونية. ومن هنا جاءت إثكالية الدراسة على النحو التالي:

ـ ما مدى رضا المستخدمين والفائدة المدركة من الحصول على الخدمات إلكترونياً في الإدارات العامة في لبنان؟

انطلاقاً من إثكالية الدراسة يمكن صياغة التساؤلات الفرعية

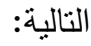

ما هي مقومات ومعوقات تطبيق الحكومة الإكترونية؟ • إلى أي مدى تطبق الحكومة الإكترونية؟، ومدى تتقيف المستخدمين بهذا المفهوم في الإدارات العامة؟ ما هو أثز استخدام الأجهزة والمعدات على رضا

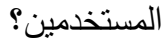
• ما هو أثز استخدام البرمجيات والثبكات على رضا

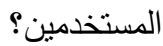
• ما هو أثز صناع المعرفة على رضا المستخدمين؟ 


\section{الفرض الفرعي الثاني}

(Ho والفائدة المدركة، ورضا المستخدمين عن الخدمات الإلكترونية

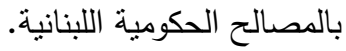

(H والفائدة الددركة، ورضا المستخدمين عن الخدمات الإلكترونية

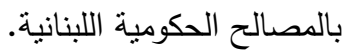
ثالثاً: أهمية الدراسة ترجع الأهمية العلمبة لهذه الدراسة لبروز فكرة إدخال النطور

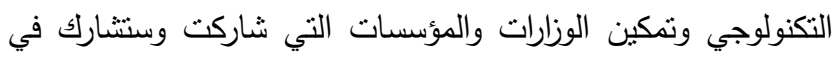
الحكومة الإلكترونية من استطلاع نسبة الإقبال والرضا عن الخدمات الإلكترونية المقدمة من خلالها. وقياس معرفة المواطن بأهمية وكيفية الحصول على الخدمات من خلال الحكومة الإلكترونية وما يترتب الإنب عليه من توفير للوقت والجهد والمال. وتكمن الأهمية العملية للاراسة فيما يلي: 1. تساعد الدراسة في عرض واقع الخدمات الإلكترونية في الوزارات العامة- لبنان والتي تخدم موظفي الوزارة والمجتمع المحلي على الدي حد سواء، ومعرفة مدى تطور وقوة قطاع تكنولوجيا المعلومات

$$
\text { والاتصالات في لبنان. }
$$

2. تحديد نقاط القوة والضعف، في الخدمات الإكترونية التي تقدمها الوزارات، وهل ساهمت في تطوير ونوحيد إجراءات العمل وسهولة انجاز الأعمال، وتوفير الوقت والجهـ والتكلفة. 3. قد تساهم تللك الدراسة في وضع مقترحات للمسؤولين وصناع القرار لمواجهة العقبات وعلاج أوجه القصور التي تواجه نطبيق الحكومة الإككترونية. إذ إنّ عملية التحول إلى الخدمة الخها

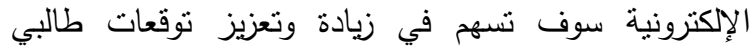

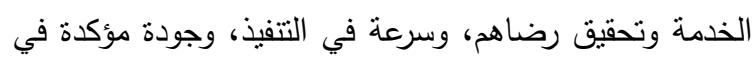

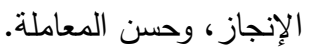
4. تزويد الجهات المعنية (الإدارة العامة لتكنولوجيا المعلومات، وزارة المالية، وزارة الصحة، وزارة العمل، وزارة التجارة

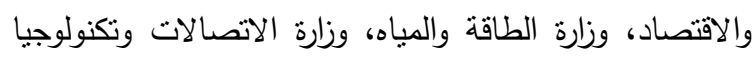
المعلومات) بدراسة تحدد مدى نجاح الخدمات الإلكترونية التي تقدمها تلك الوزارات خاصة، والحكومة الإكترونية اللبنانية

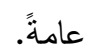

(H والثبكات والفائدة المدركة، ورضا المستخدمين عن الخدمات الإلكترونية بالمصالح الحكومية اللبنانية.

$$
\text { ب) (الفرض الرئيسي الثاني }
$$

( لا توجد علاقة ذات دلالة إحصائية بين منطلبات نجاح الحكومة الإلكترونية (الثقافة الإلكترونية وآليات النوعية)،والفائدة

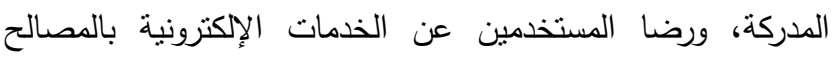

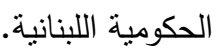

(H توجد علاقة ذات دلالة إحصائية بين منطلبات نجاح الحكومة

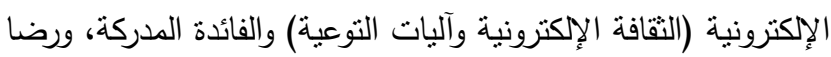
المستخدمين عن الخدمات الإلكترونية بالمصالح الحكومية اللبنانية. الفرض الرئيسي الثالث

(Ho

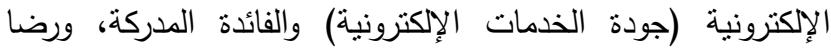
الستخدمين عن الخدمات الإلكترونية بالمصالح الحكومية اللبنانية. (H1 توجد علاقة ذات دلالة إحصائية بين مدى نجاح الخذمات

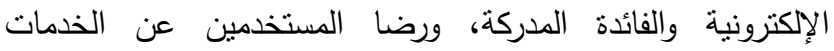
الإلكترونية بالمصالح الحكومية اللبنانية.

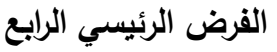
(Ho الحكومة الإلكترونية (المعوقات الإدارية، والمعوقات القانونية) والفائدة الددركة، ورضا المستخدمين عن الخدمات الإلكترونية بالمصالح

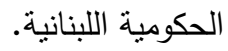

(H1 توجد علاقة ذات دلالة إحصائية بين معوقات نطبيق الحكومة الإكترونية (المعوقات الإدارية، والمعوقات القانونية) والفائدة

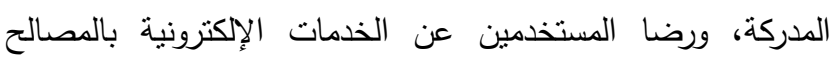

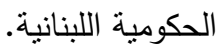
وينبثق عن هذا الفرض الفروض الفرعية التالية أ) الفرض الفرعي الأول

( لا نوجد علاقة ذات دلالة إحصائية بين المعوقات الإدارية والفائدة المدركة، ورضا المستخدمين عن الخدمات الإلكترونية بالمصالح الحكومية اللبنانية.

(H والفائدة الددركة، ورضا المستخدمين عن الخدمات الإلكترونية

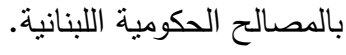




\section{سابعاً: حدود الدراسة}

لكل دراسة حدود موضوعية ومكانية وحدود زمانية:

- الحدود الموضوعية: ركزت الدراسة على تحديد الإطار

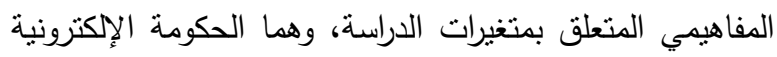

ورضا المستخدمين، من خلال مجالاتها وأساليبها.

- الحدود المكانية: بهدف الوصول إلى إثبات صحة

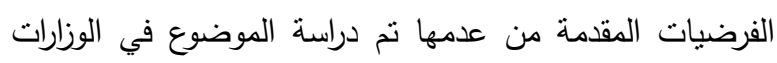
التالية (وزارة المالية، وزارة العمل، وزارة الطاقة والمياه، وزارة الصحة العامة، وزارة الاتصالات، ووزارة التجارة والاقتصاد) التي

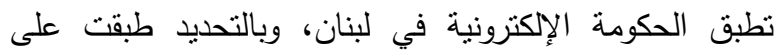
المستفيدين من الخدمات الإلكترونية بالهصالح الحكومية. - الحدود الزمانية: أجريت الدراسة في الفترة المندة من 2020/01/2 إلى 2020/02/25.

ثنامناً: الدراسات السابقة

أ) الاراسات العربية

هدفت دراسة Adwan إلى التعرف على مدى تقبل المواطنين في (قطاع غزة) للحصول على الخدمات من خلال الحكومة الإلكترونية، وقد نم جمع البيانات من المصادر الثانوية من خلال

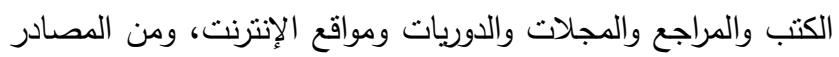
الأولية من خلال عينة من سكان (قطاع غزة) بلغت (400) فرد مقسمة على (أربع) طبقات هم موظفو القطاعين العام والخاص،

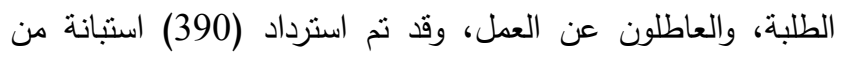

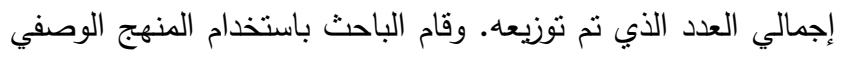

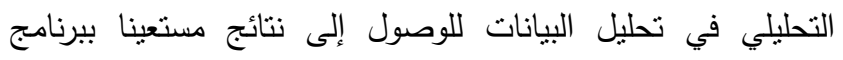

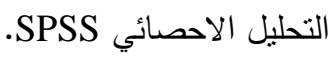

وقد أظهرت الدراسة وجود ثقبل شديد لدى المواطنين للحصول على الخدمات من خلال الحكومة الإككترونية، وقد خلصت لمجموعة من النتائج من أهمها؛ وجود قصور في استخدام آليات التوعية للتعريف بالحكومة الإككترونية، وجود وعي ودراية كبيرة لدى المواطنين

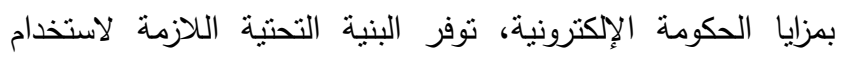

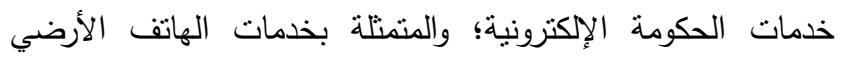
والنقال وأجهزة الحاسب الآلي وخدمة الإنترنت بشكل ملائم لاى الاى

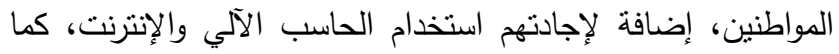
تتوفر لايهم الثقة في الخدمات الإكترونية؛ وأنه سيتم حل كافة مشاكل

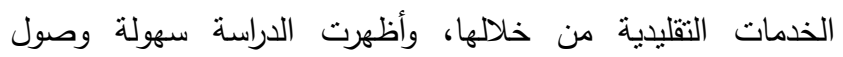
المواطنين للإنترنت في أكثر من مكان كالبيت أو العمل أو مقاهي الإنترنت، وأظهرت الدراسة أيضاً نوفر النية لدى المواطنين لاستخدام الخدمات من خلا الحكومة الإككرونية وتوفير ما بلزم لذلك.
رابعاً: أهداف الدراسة

يهذف هذا البحث إلى بناء نظرة عن رضا المستخدمين في الحصول على الخدمات الحكومية الكترونياً، وفي ضوء مشكلة البحث تم تحديد الأهداف التالية التي سعى البحث إلى تحقيقها: 1. قياس دور استخدام الوسائل التكنولوجية في نقديم الخدمات الحكومية وأثرها على رضا الدستخدمين ، والفائدة الددركة

للمستخدم.

2. تقييم درجة نوافر معايير نجاح البرمجيات والثنبكات في نظام الخدمات الحكومية داخل الإدارات ومدى تأثيرها على لئى

رضا المستخدم والفائدة المدركة.

3. تحديد العلاقة بين جودة المعلومات للخدمات الإكترونية

والفائدة المدركة للمستخدم.

4. الوقوف على المعوقات التي نواجه تطبيق الحكومة

الإلكترونية على الصعيد المحلي.

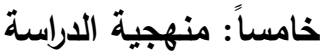

لتحقيق أهداف الدراسة، تم اعتماد المناهج النالية:

المنهج الوصفي: الذي يرتكز على الوصف الدقيق والتفصيل

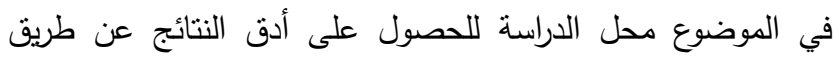
جميع المعلومات المتراكمة بخصوص الموضوع.

المنهج الاستتباطي: الذي يقوم على عمليات الاستخلاص المنطقية، من خلال وضع مجموعة من الفرضيات ثم اختبارها في الفي

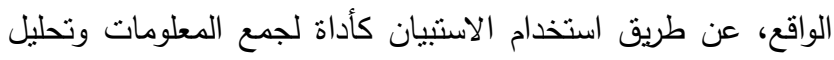

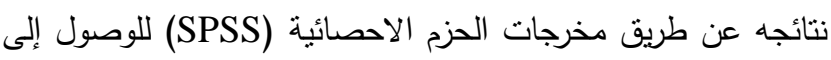

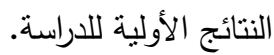

أما المعلومات الثانوية للاراسة فستتمثل في تلك المعطيات التي

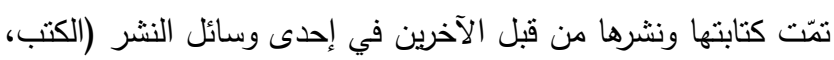
الدوريات المجلات العلمية، الأبحاث المتخصصة، الرسائل الجامعية، المواقع الالكترونية، والمؤتمرات العلمية).

\section{سادساً: مجتمع وعينة الاراسة}

يتكون مجتمع الدراسة من المستخدمين للخدمات العامة داخل الوزارات التي تطبق الحكومة الإكترونية، واستُخدمت العينة العشوائية البسيطة؛ بحيث تم اختيار المواطنين المستفيدين من الخدمات الحكومية وذللك باستخدام أرقام التلفون فقد تم ترقيمه واستخدامهم كإطار للمعاينة. وقامت الباحثة بتوزيع (384) استمارة على مستخدمي لماني

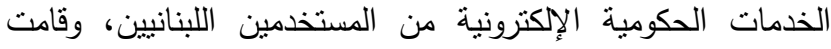
باسترداد (324) استمارة صالحة للتحليل الاحصائي لموضوع الدراسة، وبذلك تكون نسبة الاستجابة (84.38\%) وهي نسبة مقبولة إحصائياً. 
تتناول هذا الموضوع الأمر الذي يزيد فرص نجاح مشروع الحكومة الإلكترونية.

ومن بين الدراسات الأجنبية التي عالجت موضوع مقومات ومعوقات نطبيق الحكومة الإلكترونية؛دراسةFakeeh ${ }^{10}$ حيث هدفت الدراسة إلى التعرف إلى المزايا المتعلقة بفكرة الحوكمة الإككترونية،

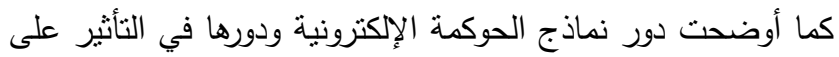

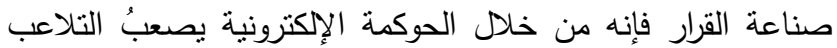

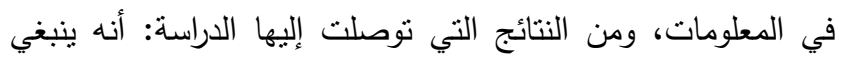

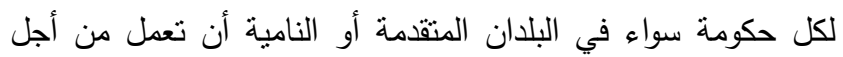
تحقيق الحكم الرقمي، إن نماذج الحكومة الإكترونية تؤثر في عملية الحكم للمواطن وتتتج حقبة جديدة من عمليات اتخاذ القرارات

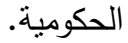

\section{الإطار النظري للاراسة}

\section{المبحث الأول}

\section{أولاً: تعريف الحكومة الإكترونية}

تبنت الأمم الدتحدة تعريفاً للحكومة الإكترونية في تقريرها

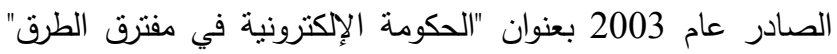
على أنها "استخدام تكنولوجيا المعلومات والاتصالات لزيادة القيمة العامة لما تقوم به الحكومة من مهام وأعمال". ثم قدم التقرير شرحاً

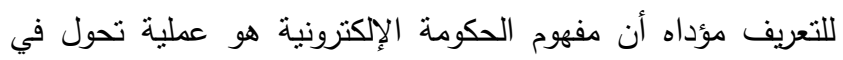
أساليب وعلاقات العمل سواء في داخل مؤسسات الحكومة أو في موني تعاملات مؤسسات الحكومة بين بعضِها البعض أي: في تعاملات

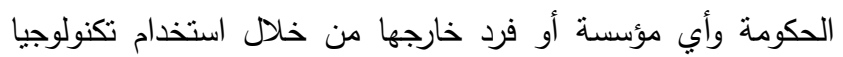

$$
\text { المعلومات والاتصالات. } 2
$$

\section{ثانياً: علاقة ثقافة المجتمع بالحكومة الإكترونية}

إن المجتمع الأكثر ثقافة على مستوى العالم ككل هو الأقرب

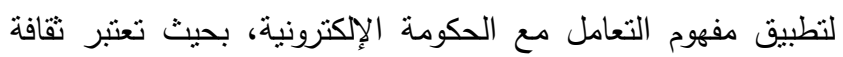

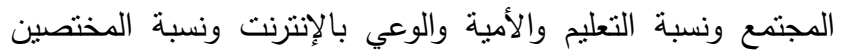
المهرة من أهم عوامل نجاح الحكومة الإكترونية. حيث إنّ التقنيات

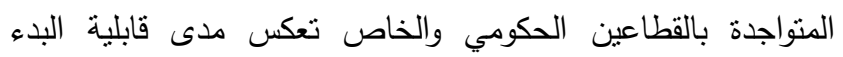

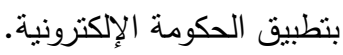

فقد وضحAl-Ghunaim أنّه على قدر عمق انتشار ثقنيات

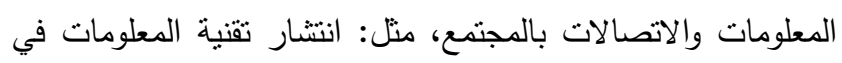
الشركات، وأعداد الحاسبات الشخصية، والهواتق الثابتة والجوالة، يتم قياس المؤشرات التي تدل على جاهزية المجتمع بكافة شرائحه للبدء

بتطبيق الحكومة الإلكترونية.

فالبيئة التي يعي فيها كل عنصر من عناصرها وهم المواطن والحكومة والقطاع الخاص أهمية التعاون على تقريب المسافات وتذليل
في حين تمحورت أهداف دراسة Ibrahim\&Ali؛ في بيان مدى تقبل المكلفين لتطبيق الحكومة الإلكترونية في الهيئة العامة للضرائب، فضلاً عن تقييم مدى توفر تقنية الدعلومات في الهيئة؛ التي لئي تمكنها من نطبيق الحكومة الإلكترونية. وأوضحت الدراسة وجود أثز إيجابي لنطبيق الحكومة الإلكترونية في تحسين مسنوى الإذعان

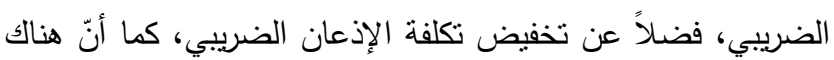
تقبُّلاً لفكرة تطبيق الحكومة الإككترونية من قبل المكلفين.

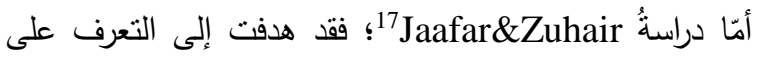

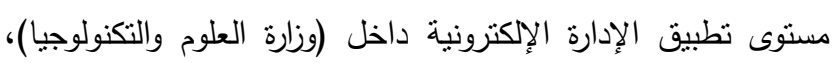

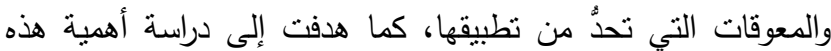
المنطلبات وترتييها وتأثيرها على مبادئ إدارة الجودة الثاملة في الوزارة المبحوثة. واعتمد الباحث على منهج دراسة الحالة، وتوصل إلى نتائج

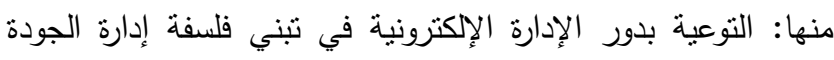

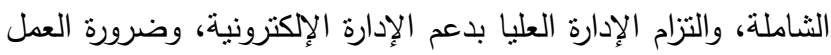

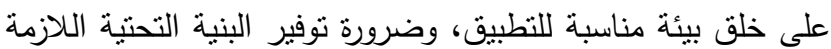
للعمل داخل الوزارة. ومن أهم التوصيات؛ توفير المخصصات المالية اللازمة، تشجيع الكفاءات البشرية، الاستفادة من تجارب الدول الداتل السابقة، وضرورة استخدام الإدارة الإلكترونية في دوائر الوزارة للتوصل الى تطبيق الحكومة الإكترونية على مستوى الوزارة ككل.

\section{الدراسات الأجنبية}

هدفت دراسة Sandh \&Younas توقعات المواطنين في (باكستان) حيال الخدمات الإلكترونية، وما الذي دراني يريدون الحصول عليه من خلالها، إضافة للتعرف على الوفالت الإسائل

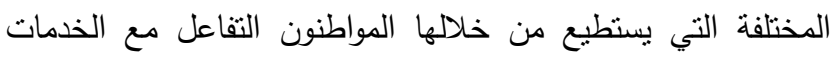
الإلكترونية ومدى فعالية هذه الوسائل.

وقد تم استخدام المنهج الوصفي التحليلي في الدراسة، وتمّ جمع البيانات من خلال المقابلات الثخصية والتلفونية ونوزيع الاستبانة عبر البريد والفاكس على المواطنين؛ بحيث يتم التركيز على دراسة (133) خدمة إلكترونية، وسبل تفاعل المواطنين مع هذه الخدمات، وما هي نوقعات المواطنين حيالها، والتحسينات التي يريد المواطنون

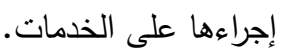

وقد توصلت الدراسة لعدة نتائج من أهمها أنّ (باكستان) لا تزال

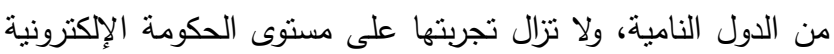
تحت المستوى المتوسط؛ قياساً بمستوى تجارب بعض الدول في هذا المضمار، وأظهرت الدراسة أن المواطنين غير مهتمين باستخدام

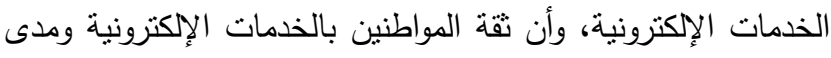
مقابلتها لتوقعاتهم تزيد من فرص نجاح الحكومة الإلكترونية، وكذلك الكان

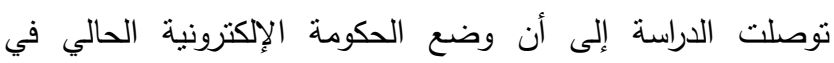
(باكستان) بحاجة للحصول على تفاصيل كثيرة من خلال دراسات 
رضا المستخدم، الاستخدام، التأثير الثخصي، الثأثثر المؤسسي، فعالية النظام، ومدى تأثيره على المؤسسة ككل 15.

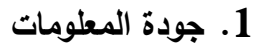

تهتم نوعية المعلومات بما يحتويه النظام من بيانات ومعلومات بالتركيز على خصائصها مثل: الاقة الاكتمالية، الإيجاز، الصلة بالموضوع، أن تكون مفهومة وذات معنى، قابلة للمقارنة، وذات شكل

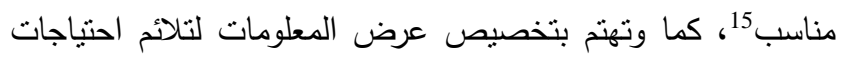

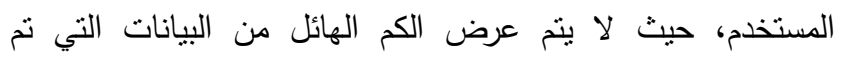
تخزينها، والمعلومات التي تم معالجتها، إلا بناءٌ على احتياجات

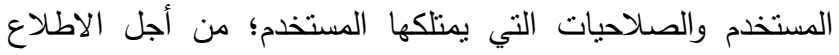
على المعلومات، حيث ينبغي أن يحتوي النظام على نظام ذكاء لتزويد المستخدمين بإمكانية الوصول إلى المعلومات الصحيحة في الوقت المناسب، للمساعدة على اتخاذ القرارات الصائبة، ويزودهم بإمكانية

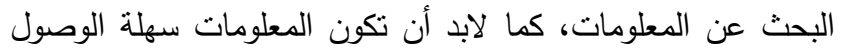

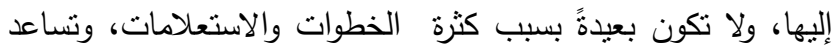

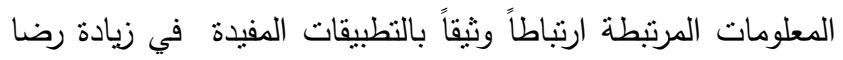
المستخدمين بشكل إيجابي.6

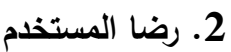

يتضمن هذه البعد قياس استجابة المستخدمين لنظام الخدمات

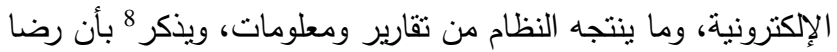
المستخدم يشير إلى التفاعل الناجح بين نظام المعلومات نفسه ومستخدميه، ومدى توافقه مع احتياجاتهم وتطلعاتهم من هذا النظام

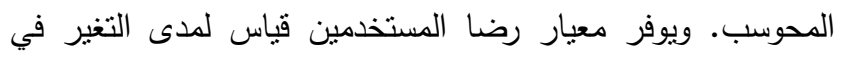
كفاءة المؤسسة بعد نطبيق نظام المعلومات، كما وينظر 19 إلى رضا المستخدمين من حيث استخدام النظام وتقبل العمل عليه على أنه مقياس عملي لنجاح النظام. الإطار العملي للادراسة

\section{أولاً: تحديد حجم عينة الدراسة}

قامت الباحثة بتحديد حجم العينة التي تم توزيعها على مستخدمي الخدمات الإكترونية حسب المعادلة التالية:

$$
\begin{gathered}
\mathrm{n}=\left(\frac{z_{\mathrm{x} / 2}}{E}\right)^{2} \times p q \\
\text { حيث إنّ } \mathrm{n}
\end{gathered}
$$

Z: القيمة الجدولية المستخرجة من جدول التوزيع الطبيعي عند مسنوى ثقة معين.

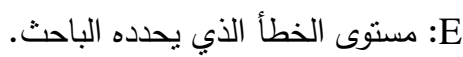

العقبات التي تقف حائلاً أمام الإنجاز والتتمية، وتبني الأفكار الني

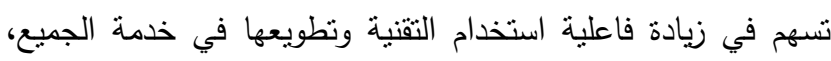
عندها يتم إيجاد بيئة عمل إلكترونية مناسبة يمكن من خلالها تحقيق الأهداف التتموية من خلال التطبيق السليم لآليات الحكومة

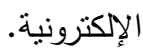

\section{المبحث الثاني: الخدمات الحكومية الإكترونية}

\section{أولاً: مفهوم الخدمات الحكومية الإكترونية}

يقصد (بالخدمات الحكومية) بالثكل التقليدي أن ينم نقديم

الخدمات بطريقة شخصية (Face to Face)، وفي هذه الحالة ينوجه صاحب الطلب إلى مكان تقديم الخدمة ويقابل المسؤولين عن هذه

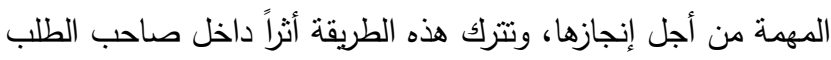

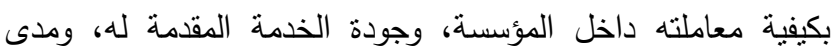
كفاءة المؤسسة. ويمكن تعريف (الخدمات الحكومية) على أنها "مزيج متكامل من بعض البنود مثل العمليات، والموظفين، والعملاء والموارد الثقنية والمالية، والهيكل التنظيمي للمؤسسة". 12 وتعني (الخدمات الإلكترونية) إنجاز الخدمات الحكومية بطريقة معلوماتية تعتمد على الإنترنت ووفق ضرورات أمنية معينة تحمي المستقيد والجهة صاحبة الخدمة، ويتمتل ذلك في استخدام تكنولوجيا المعلومات والاتصالات لتحسين وتدبير شؤون العامة.13 ثانياً: نموذج نجاح نظم المعلومات يعد نموذج عوامل نجاح نظم المعلومات (D\&M) والذي توصل إليه الباحثان"Delone and Mclean" عام (1992) من النماذج المستخدمة لقياس نجاح نظم المعلومات، ويعثبر الغرض الرئيسي منه

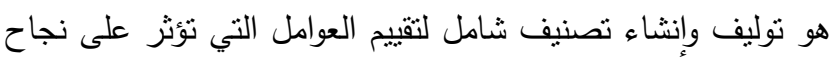

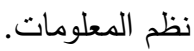
وقد عرض النموذج المتغيرات الرئيسية الستة لنجاح نظام المعلومات

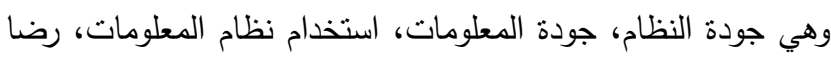

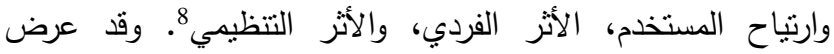
النموذج العلاقة بين المتغيرات وتأثيرها على بعضها البعض، حيث التي التردي

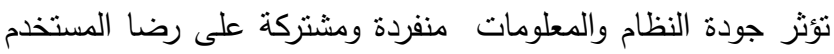
وعلى استخدام النظام، بالإضافة إلى ذللك، يمكن أن يؤنز مقدار

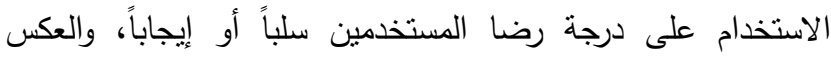

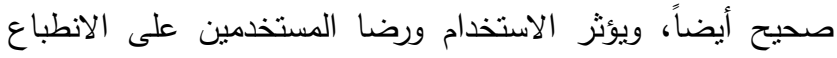

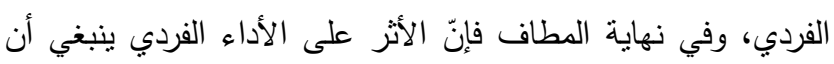

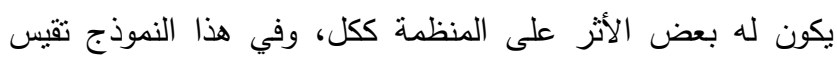
جودة النظام النجاح الفني، وجودة المعلومات تقبس لإنى مدى نجاح المعلومات في تقديم المعاني والمفاهيم المطلوبة، فيما بقيس كُكلًا من 
قامت الباحثة بنوزيع (384) استمارة على مستخدمي الخدمات الحكومية الإلكترونية من المستخدمين اللبنانيين، وقامت باسترداد (324) استمارة صالحة للتحليل الاحصائي لموضوع الدراسة، وبذلك نكون نسبة الاستجابة (84.38\%) وهي نسبة مقبولة إحصائياً. 2. التحليل الوصفي لاستمارة استقصاءالمستخدمين قامت الباحثة بعمل التحليل الوصفي لاستمارة الاستقصاء التي قامت بتوجيها إلى عينة الدراسة من المستخدمين لخدمات الحكومة اللبنانية الإلكترونية محل الدراسة، حيث يضم التحليل

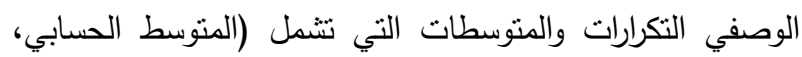

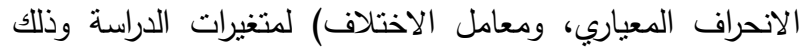

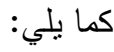

• التكرارات للمتغيرات الديموغرافية 1. تكرارات الجنس للعينة محل الدراسة جدول رقم (3): تكرارات الجنس للعينة محل الدراسة

\begin{tabular}{|c|c|c|}
\hline النسبة المئوية (\%) & التكرار & البيان البيان \\
\hline 56.17 & 182 & ذكر \\
\hline 43.83 & 142 & أنثى \\
\hline 100.00 & 324 & الإجمالى \\
\hline
\end{tabular}

* الجدول من إعداد الباحثة بناء على مخرجات التحليل الإحصائي

يتضح من الجدول السابق أن عدد (الذكور) من العينة محل الدراسة هو (182) مفردة؛ بما يمثل (56.17\%) من إجمالي العينة محل الدراسة، وبلغ عدد (الإناث) من العينة محل الدراسة (142) مفردة؛ بما يمتل (43.83\%) من إجمالي العينة محل الدراسة. 2. تكرارات العمر للعينة محل الدراسة جدول رقم (4): تكرارات العمر للعينة محل الدراسة:

\begin{tabular}{|c|c|c|}
\hline النسبة المئوية (\%) & التكرار & البيان \\
\hline 1.85 & 6 & أقل من 20 سنة \\
\hline 23.46 & 76 & بين 21 و 30 سنة \\
\hline 35.80 & 116 & بين 31 و 40 سنة \\
\hline 38.89 & 126 & فوق 40 سنة \\
\hline 100.00 & 324 & الإجمالي \\
\hline
\end{tabular}

"الجدول من إعاد الباحثة بناء على مخرجات التحليل الإحصائي "
ن نسبة نوافر الصفة في المجتمع محل الدراسة.

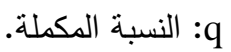
وبفرض أنّ مسنوى الثقة المطلوب هو (95\%) ونسبة الخطأ (5\%) وأنّ نسبة الصفة في المجتمع هي (0.5\%)، وبالتالي تكون قيمة (q) هي (0.5\%)، وبذلك تصبح المعادلة على النحو النالي: ${ }^{9}\left(n=\left(\frac{1.96}{0.05}\right)^{2} \times 0.5 \times 0.5=384\right.$ Tull \& Hawkins $)$ وقد قامت الباحثة بتوزيع (384) مفردة تفادياً لأي أخطاء أثناء التجميع، استردت منهم (324)، وهي ما تمثل (84.38\%) من حجم العينة المطلوب، وهي نسبة كافية إحصائياً. ثانياً: الأساليب الإحصائية المستخدمة

قامت الباحثة بعمل الدراسة الميدانية للدراسة باستخدام مجموعة من الأساليب الإحصائية، وذلك كما يلي: 1. تم استخدام برنامج التحليل الإحصائي (SPSS) الإصدار 25، وذلك للتوصل إلى نتائج التحليل. 2. التحليل الوصفي، حيث تم استخدام المتوسط الحسابي، الانحراف المعياري، ومعامل الاختلاف.

3. الانحدار البسيط، وتم استخدامه بغرض قياس العلاقات بين متغيرات الدراسة.

4. تم الاعتماد في التحليل الوصفي على استخدام توصيف

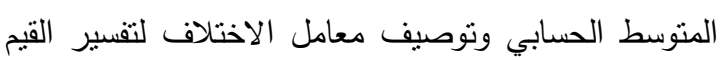
الناتجة عن التحليل الوصفي، وذلك كما يلي: جدول رقم (1): توصيف المتوسط الحسابي 11

\begin{tabular}{|c|c|c|c|c|}
\hline $5: 4.2$ & من 3.4 : أقل & 2.6 : أقل 3.4 & من 1.8 : أقل 2.6 & 1 من : أقل 1.8 \\
\hline أتفق تماماً & أتفق & محايد & لا أتفق & لا لأفق \\
\hline
\end{tabular}

جدول رقم (2): توصيف معامل الاختلاف55

\begin{tabular}{|c|c|c|c|c|c|}
\hline $\begin{array}{l}\text { فأكثر 60 } \\
\text { ف }\end{array}$ & $\begin{array}{l}\text { أقل من \%0 } \\
\text { \%00 }\end{array}$ & $\begin{array}{l}\text { أقل من \% } \\
\text { \% 40 } \\
\text { \% }\end{array}$ & $\begin{array}{l}\text { أقل من \% } \\
\text { \%20 }\end{array}$ & من 5\% : أقل & 0 \\
\hline الاختلاف & واضح & الاختلاف & الاختلاف & محدود & لا يوتلاف \\
\hline
\end{tabular}
التحليل الإحصائي للاستبيان:

1. نسب استجابة المستخدمين للذدمات الإكترونية: 
(25.93\%) من إجمالي العينة محل الدراسة، وبلغ عدد الحاصلين على المؤهل (الجامعي) من العينة محل الدراسة (214) مفردة؛ بما لمانه يمثل (66.05\%) من إجمالي العينة محل الدراسة. جدول رقم (5): تكرارات المستوى العلمي للعينة محل الدراسة

\begin{tabular}{|c|c|c|}
\hline النسبة المئوية (\%) & الت التكرار & 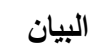 \\
\hline 8.02 & 26 & أساسي \\
\hline 25.93 & 84 & ثانوي \\
\hline 66.05 & 214 & جامعي \\
\hline 100.00 & 324 & الإجمالي \\
\hline
\end{tabular}

" الجدول من إعداد الباحثة بناء على مخرجات التحليل الإحصائي 4. تكرارات المهنة للعينة محل الاراسة

يتضح من الجدول السابق أنّ عدد الذين (يقل عمرهم عن 20 سنة) من العينة محل الدراسة هو (6) مفردات؛ بما يُمنتل (1.85\%) من إجمالي العينة محل الدراسة، وبلغ عدد الذين يتراوح عمرهم بين الدين (21 و30 سنة) من العينة محل الدراسة (76) مفردة؛ بما يمثل (23.46\%) من إجمالي العينة محل الدراسة، وبلغ عدد الذين يتراوح

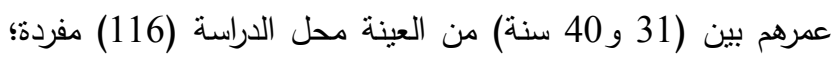
بما يمنل (35.80\%) من إجمالي العينة محل الدراسة، وبلغ عدد العنة الذين يفوق عمرهم (40 سنة) من العينة محل الدراسة (126) مفردة؛ بما يمثل (38.89\%) من إجمالي العينة محل الدراسة. 3. تكرارات المستوى العلمي للعينة محل الدراسة

يتضح من الجدول رقم (5) أن عدد الحاصلين على المؤهل

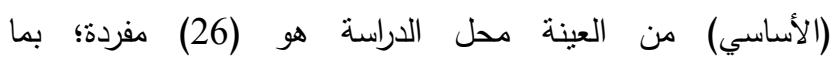
يمثل(8.02\%) من إجمالي العينة محل الدراسة، وبلغ عدد الحاصلين على المؤهل (الثانوي) من العينة محل الدراسة (84) مفردة؛ بما يمثل جدول رقم (6): تكرارات المهنة للعينة محل الدراسة

\begin{tabular}{|c|c|c|}
\hline النسبة المئوية (\%) & التكرار & 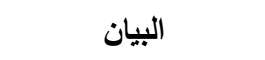 \\
\hline 0.62 & 2 & صيدلي \\
\hline 1.23 & 4 & أعمال حرة \\
\hline 1.54 & 5 & 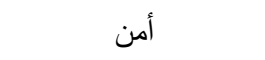 \\
\hline 2.16 & 7 & صاحب مؤسسة \\
\hline 2.16 & 7 & مصمم جرافيك \\
\hline 2.16 & 7 & مصور فوتوغرافي \\
\hline 2.78 & 9 & محاضر جامعي \\
\hline 3.09 & 10 & مدير إداري \\
\hline 3.40 & 11 & طالب جامعي \\
\hline 4.32 & 14 & طب \\
\hline 4.63 & 15 & وظائف منتوعة \\
\hline 4.63 & 15 & تاجر \\
\hline 4.63 & 15 & مهندس \\
\hline 4.94 & 16 & مندوب دعاية ومبيعات \\
\hline 7.41 & 24 & حرفي \\
\hline 8.02 & 26 & بدون عمل \\
\hline
\end{tabular}




\begin{tabular}{|c|c|c|}
\hline النسبة المئوية (\%) & التكرار & البيان \\
\hline 8.02 & 26 & محاسبة \\
\hline 12.04 & 39 & موظف إداري \\
\hline 22.22 & 72 & 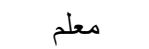 \\
\hline 100.00 & 324 & الإجمالي \\
\hline
\end{tabular}

* الجدول من إعداد الباحثة بناء على مخرجات التحليل الإحصائي

تكرارات قطاع العمل للعينة محل الدراسة

جدول رقم (7): تكرارات قطاع العمل للعينة محل الدراسة

\begin{tabular}{|c|c|c|}
\hline النسبة المئوية (\%) & التكرار & البيان \\
\hline 17.28 & 56 & قطاع عام \\
\hline 62.65 & 203 & قطاع خاص \\
\hline 20.06 & 65 & لا ينطبق \\
\hline 100.00 & 324 & الإجمالي \\
\hline
\end{tabular}

* الجدول من إعداد الباحثة بناء على مخرجات التحليل الإحصائي يتضح من الجدول السابق أنّ عدد العاملين (بالقطاع العام) من العينة محل الدراسة هو (56) مفردة؛ بما يمثل (17.28\%) من

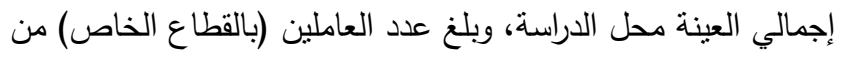

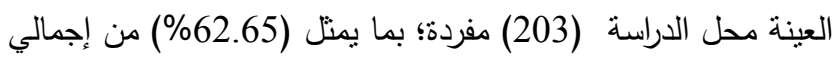

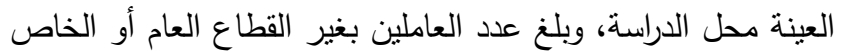
(65) مفردة؛ بما يمثل (20.06\%) من إجمالي العينة محل الدراسة.

\section{ثنالثاً: صدق وثبات المقاييس}

\section{أ) أ) صدق المفاهيم النظرية}

تم قياس صدق المفاهيم النظرية المجربة باستخدام تحليل

العامل (factor analysis) والذي بعتمد على المقاييس التالية: • والتي تقيس مدى ملائمة المقياس ويُعدّ الحد الأدنى المقبول

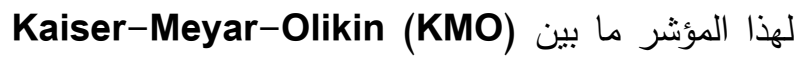

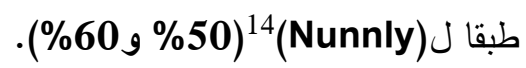
Bartlett of Sphericity معيناً من المعنوية حيث يجب أن تكون قيمة

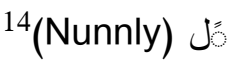

يتضح من الجدول السابق أنّ عدد العاملين بمهنة (صيدلي)

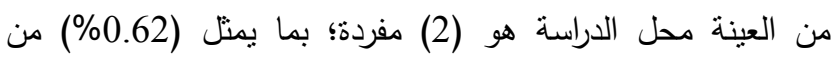

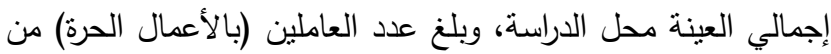
العينة محل الدراسة (4) مفردات؛ بما يمثل (1.23\%) من إجمالي

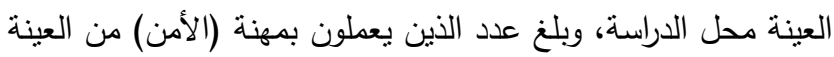

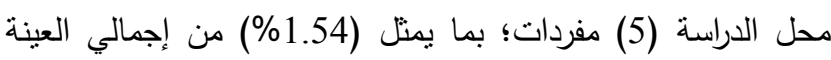

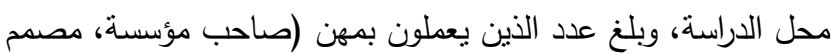
جرافيلك، ومصور فوتوغرافي) من العينة محل الدراسة (7) مفردات لكل منهم؛ بما يمثل (2.16\%) من إجمالي العينة محل الدراسة لكل منهم، وبلغ عدد الذين يعملون بمهنة (محاضر جامعي) من العينة محل الدراسة (9) مفردات؛ بما بمثل (2.78\%) من إجمالي العينة محل الدراسة، وبلغ عدد الذين بعملون بمهنة (مدير إداري) من العينة محل الدراسة (10) مفردات؛ بما بمثل (3.09\%) من إجمالي العينة محل الدراسة، وبلغ عدد (الطلبة الجامعيين) من العينة محل الدراسة (11) مفردة؛ بما يمثل (3.40\%) من إجمالي العينة محل الدراسة،

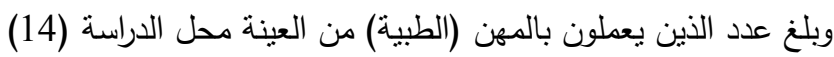
مفردة؛ بما يمثل (4.32\%) من إجمالي العينة محل الدراسة، وبلغ

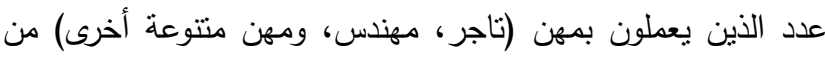
العينة محل الدراسة (15) مفردة؛ بما يمثل (4.63\%) من بن إجمالي العينة محل الدراسة، وبلغ عدد الذين بعملون بمهنة (مندوب دعاية ومبيعات) من العينة محل الدراسة (16) مفردة؛ بما يمنل (4.94\%) من إجمالي العينة محل الدراسة، وبلغ عدد الذين يعملون بالمهن (الحرفية) من العينة محل الدراسة (24) مفردة؛ بما يمثل (7.41\%)

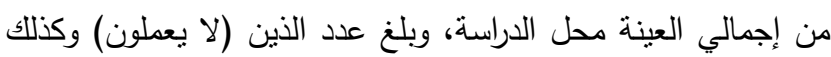
العاملين بمهن (المحاسبة) من العينة محل الدراسة (26) مفردة لكل منهما؛ بما يمثلان (8.02\%) من إجمالي العينة محل الدراسة لكل

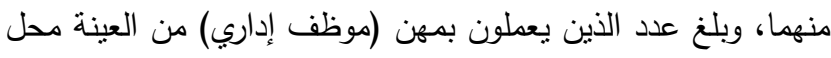
الدراسة (39) مفردة؛ بما يمثل (12.04\%) من إجمالي العينة محل

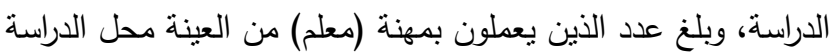
(72) مفردة؛ بما يمثل (22.22\%) من إجمالي العينة محل الدراسة. 
جدول رقم (8) صدق المفاهيم النظرية لمحاور الدراسة للاستبانة المتعلقة بالمستخدمين باستخدام KMO, Bartlett of sphere city

\begin{tabular}{|c|c|c|c|c|}
\hline$P$ value & KMO & عدد الفقرات & 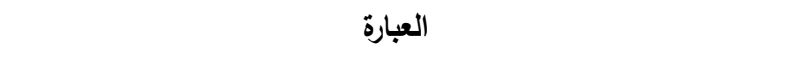 & b \\
\hline 0.000 & 0.705 & 4 & حصول المستخدمين على الوسائل التكنولوجية & 1 \\
\hline 0.000 & 0.633 & 4 & استخدام البرمجيات والشبكات & 2 \\
\hline 0.000 & 0.818 & 3 & مدى نجاح الخدمات الإلكترونية (جودة الخدمات الإلكترونية) & 3 \\
\hline 0.000 & 0.517 & 3 & منطلبات نجاح الحكومة الإكترونية ( الثقافة الإلكترونية وآليات التوعية) & 4 \\
\hline 0.000 & 0.517 & 5 & المعوقات القانونية والادارية & 5 \\
\hline 0.000 & 0.771 & 5 & الفائدة المدركة من استخدام النظام & 6 \\
\hline 0.000 & 0.517 & 2 & رضا المستخدمين & 7 \\
\hline
\end{tabular}

* الجدول من إعداد الباحثة بناء على مخرجات التحليل الإحصائي

ب) ثبات أداة الدراسة

يعد الثبات المقياس الأول والمقبول لتقييم جودة أي الثبات وطبقاً ل (Nunnly)14 فإن الحد الأدنى لهذه المعامل ما بين

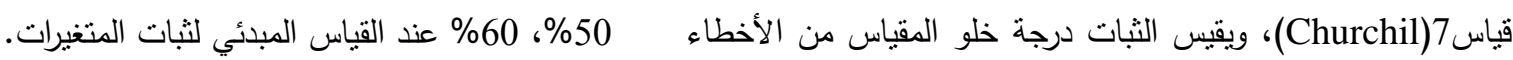

(Zikmund)18) جدول رقم (9) معامل الثبات لمحاور الدراسة للاستبانة المتعلقة بالمستخدمين باستخدام طريقة معامل ألفا كرو نباخ

\begin{tabular}{|c|c|c|c|}
\hline معامل ألفا كرو نباخ & 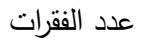 & 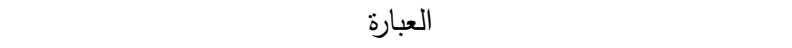 & r \\
\hline 0.673 & 4 & حصول المستخدمين على الوسائل التكنولوجية & 1 \\
\hline 0.653 & 4 & استخدام البرمجيات والثبكات & 2 \\
\hline 0.657 & 3 & مدى نجاح الخدمات الإككترونية (جودة الخدمات الإلكترونبة) & 3 \\
\hline 0.682 & 3 & منطلبات نجاح الحكومة الإلكترونية ( الثقافة الإلكترونية وآليات التوعية) & 4 \\
\hline 0.741 & 3 & 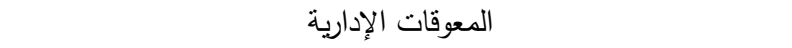 & 5 \\
\hline 0.740 & 2 & المعوقات القانونية المونية & 6 \\
\hline 0.660 & 5 & الفائدة المدركة من استخدام النظام & 7 \\
\hline 0.637 & 2 & رضاء المستخدمين & 8 \\
\hline
\end{tabular}

* الجدول من إعداد الباحثة بناء على مخرجات التحليل الإحصائي رابعاً: تحليل النتائج

أ. التحليل الوصفي (المتوسطات) للمستخدمين للذدمات الإكترونية 1. المتغير المستقل الفرعي: الحكومة الإكترونية 
جدول رقم (10): التحليل الوصفي (المتوسطات) للمتغير الفرعي (الحكومة الإكترونية)

\begin{tabular}{|c|c|c|c|c|c|}
\hline الاختلاف معامل \% & الانحراف & الصسابي & العينة & العبارة & e \\
\hline 27.27 & 1.02 & 3.75 & 324 & بإمكاني شراء حاسوب في أي وقت & 1 \\
\hline 32.18 & 1.15 & 3.57 & 324 & من السهل الحصول على شبكة إنترنت بسعر مناسب & 2 \\
\hline 24.91 & 0.98 & 3.94 & 324 & أستطيع العمل على الإنترنت في أكثر من مكان & 3 \\
\hline 16.84 & 0.73 & 4.34 & 324 & تتوافر لاى الوزارة أجهزة حاسوب تلبي احتياجات تطبيقات الحكومة الإككرونية & 4 \\
\hline 18.97 & 0.76 & 4.00 & & المتغير الكلي لحصول المستخدمين على الوسائل التكنولوجية & 5 \\
\hline 36.57 & 1.13 & 3.08 & 324 & استخدم موقع أجيرو للاطلاع مثلاً على مستوى استهلاكي للإنترنت & 6 \\
\hline 36.70 & 1.18 & 3.23 & 324 & عذدما أقرر الحصول على خدمة حكومية أزور موقع الوزارة على الانترنت & 7 \\
\hline 31.20 & 1.12 & 3.58 & 324 & لدي الاستعداد الكامل للتعامل مع الأنظمة الإلكترونية للوزارات & 8 \\
\hline 20.41 & 0.79 & 3.87 & 324 & أفضّل النعامل مع ليبان بوست في المسائل البريدية & 9 \\
\hline 21.04 & 0.76 & 3.64 & & المتغير الكلي لاستخذام البرمجيات والثبكات & 10 \\
\hline
\end{tabular}

* الجدول من إعداد الباحثة بناء على مخرجات التحليل الإحصائي

بانحراف معياري قيمته (0.73)، وبلغ معامل الاختلاف (16.84\%)، وهذا يعني وجود اختلاف محدود بين آراء العينة محل الدراسة حول هذا المتغير.

5. بلغت قيمة المتوسط الحسابي للمنغير الكلي لحصول المستخدمين على الوسائل التكنولوجية (4.00)، وهذا يعني أنها تقع في توصيف الموافقة، بانحراف معياري قيمته (0.76)، وبلغ معامل الاختلاف (18.97\%)، وهذا بعني وجود اختلاف محدود بين آراء العينة محل الدراسة حول

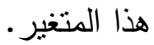
6. بلغت قيمة المنوسط الحسابي لمتغير استخدام موقع أجيرو

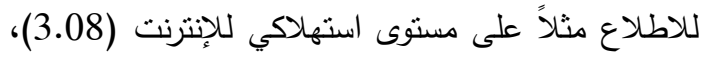
وهذا يعني أنها تقع في توصيف المحايد، بانحراف معياري قيمته (1.13)، وبلغ معامل الاختلاف (36.57\%)، وهذا يعني وجود اختلاف واضح بين آراء العينة محل الدراسة حول هذا المتغير، ويتبين من الجدول التالي لحساب

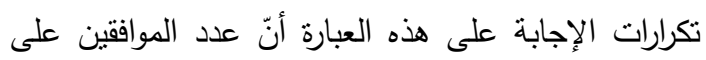
تواجد هذا المتغير (141) مفردة؛ بنسبة (43.52)، وعدد غير الموافقين (145) مفردة؛ بنسبة (144.75)، وهذا يدل على ميل إجابات المستقصي منهم محل الدراسة نحو عدم الموافقة على توافر هذا المتغير.

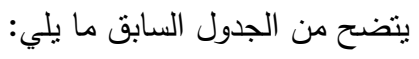

1. بلغت قيمة المتوسط الحسابي لمتغير إمكانية شراء حاسوب في أي وقت (3.75)، وهذا يعني أنها تقع في توصيف الموافقة، بانحراف معياري قيمته (1.02)، وبلغ معامل الاختلاف (27.27\%)، وهذا يعني وجود اختلاف واضح بين آراء العينة محل الدراسة حول هذا المتغير. 2. بلغت قيمة المتوسط الحسابي لمتغير سهولة الحصول على

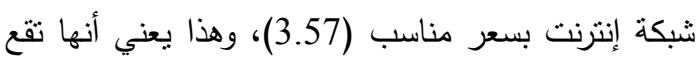

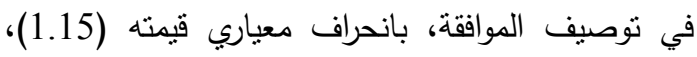
وبلغ معامل الاختلاف (32.18\%)، وهذا بعني وجود

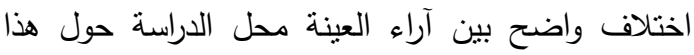

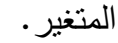
3. بلغت قيمة المتوسط الحسابي لمتغير إمكانية العمل على الإنترنت في أكثر من مكان (3.94)، وهذا يعني أنها تقع لقعي في توصيف الموافقة، بانحراف معياري فيمته (0.98)، وبلغ الانترن

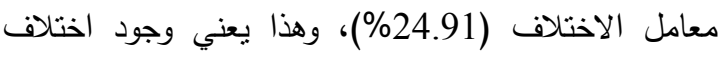
واضح بين آراء العينة محل الدراسة حول هذا المتغير. 4. بلغت قيمة المتوسط الحسابي لمتغير تتوافر لدى الوزارة أجهزة حاسوب تلبي احتياجات تطبيقات الحكومة الإلكترونية (4.34)، وهذا بعني أنها نقع في توصيف الموافقة بشدة، 
أ.التحليل الوصفي (المنوسطات) للمتغير المستقل (النقافة الإكترونية وآليات التوعية بمفهوم الحكومة الإلكترونية)
2. المتغير المستقل الفرعي: متطلبات نجاح الحكومة

الإكترونية

جدول رقم (11): التحليل الوصفي (المتوسطات) للمتغير الفرعي (آليات التوعية بمفهوم الحكومة الإلكترونية)

\begin{tabular}{|c|c|c|c|c|}
\hline الاختلاف \% معامل & الانحراف & الحسابي & العينة & العبارة \\
\hline 43.19 & 1.20 & 2.78 & 324 & يوجد إعلانات في الصحف والتلنيزيون شترح مفهوم الحكومة الإلكترونية \\
\hline 46.14 & 1.18 & 2.57 & 324 & نتعق ندوات في الجمعيات الأهلية لثرح مفهوم الحكومة الإلكترونية \\
\hline 48.16 & 1.27 & 2.63 & 324 & توجد نشرات توضيحية تشرح مفهوم الحكومة الإلكترونية في مقرات الدوائر الحكممية \\
\hline 42.42 & 1.13 & 2.67 & & المتغير الكلي لآليات التوعية بفهوم الحكومة الإلكترونية \\
\hline
\end{tabular}

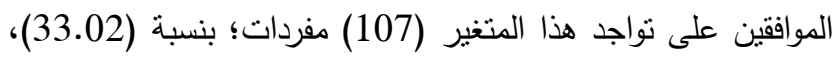

الجدول من إعاد الباحثة بناء طلى مخرجات التحليل الإحصائي

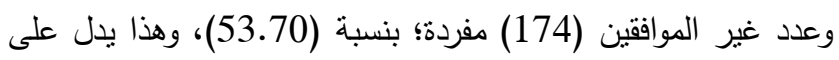
يتضح من الجدول السابق ما يلي: ميل إجابات المستقصي منهم محل الدراسة نحو عدم الموافقة على الى نوافر هذا المتغير. 1- بلغت قيمة المتوسط الحسابي لمتغير وجود إعلانات في الصحف والتليفزيون تشرح مفهوم الحكومة الإكترونية (2.78)، وهذا 3. المتغير المستقل الفرعي: مدى نجاح الخدمات الإكترونية: يعني أنها تقع في توصيف المحايد، بانحراف معياري قيمته (1.20)،

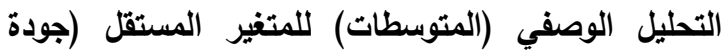

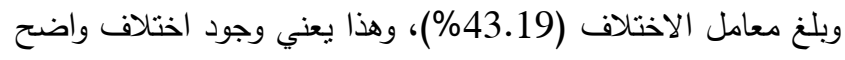

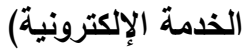

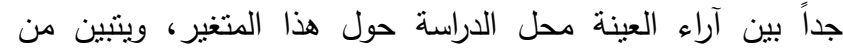
الجدول الثالي لحساب تكرارات الإجابة على هذه العبارة أنّ عدد العنية جدول رقم (12): التحليل الوصفي (المتوسطات) للمتغير الفرعي (جودة الخدمة الإكترونية)

\begin{tabular}{|c|c|c|c|c|c|}
\hline $\begin{array}{c}\text { معامل } \\
\text { الاختلاف } \\
\text { \% }\end{array}$ & الانعراف & الحسابوسط & العينة & 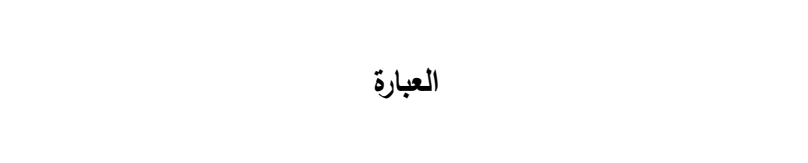 & 5 \\
\hline 22.74 & 0.80 & 3.53 & 324 & المعلومات المتوفرة من الخدمات الالكترونية مفهومة & 1 \\
\hline 23.13 & 0.81 & 3.49 & 324 & عدد الخطوات المطلوبة لإنهاء المهام على موقع الخدمات الإلكترونية قليل & 2 \\
\hline 25.10 & 0.89 & 3.54 & 324 & طورت الخدمات الالكترونية من مستوى جودة عمليات الوزارة & 3 \\
\hline 21.87 & 0.77 & 3.52 & & المتغير الكلي لجودة الخدمة الإلكترونية & 4 \\
\hline
\end{tabular}

2- بلغت قيمة المتوسط الحسابي لمتغير قلة عدد الخطوات المطلوبة لإنهاء المهام على موقع الخدمات الإلكترونية (3.49)،

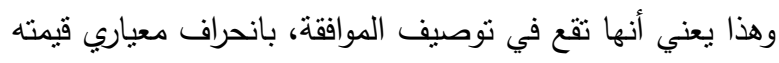
(0.81)، وبلغ معامل الاختلاف (23.13\%)، وهذا بعني وجود اختلاف واضح بين آراء العينة محل الدراسة حول هذا المتغير. 3- بلغت قيمة المتوسط الحسابي لمتغير تطوير الخدمات

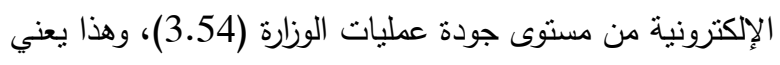
أنها تقع في توصيف الموافقة، بانحراف معياري قيمته (0.89)،
الجدول من إعداد الباحثة بناء على مخرجات التحليل الإحصائي

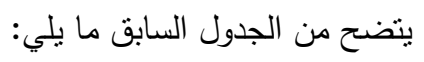

1- بلغت قيمة المتوسط الحسابي لمتغير فهم المعلومات

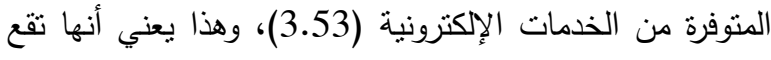

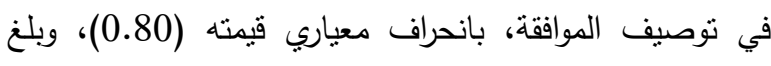
معامل الاختلاف (22.74\%)، وهذا يعني وجود اختلاف واضح بين آراء العينة محل الدراسة حول هذا المتغير. 
(21.87\%)، وهذا يعني وجود اختلاف واضح بين آراء العينة

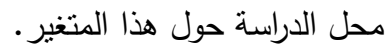

4- المتغير المستقل الفرعي: معوقات تطبيق الحكومة الإلكترونية

أ) التحليل الوصفي (المتوسطات) للمتغير المستقل (المعوقات

(الإدارية)

جدول رقم (13): التحليل الوصفي (المنوسطات) للمتغير الفرعي (المعوقات الإدارية)

\begin{tabular}{|c|c|c|c|c|c|}
\hline $\begin{array}{c}\text { الاختلاف } \\
\text { معامل }\end{array}$ & الانعراف & الحسابي & العينة & العبارة & 5 \\
\hline 41.78 & 1.13 & 2.70 & 324 & أجد صعوبة في التعامل مع البوابات الإلكترونية الحكومية & 1 \\
\hline 36.43 & 1.01 & 2.78 & 324 & صعوبة مواقع الخدمات الإلكترونية على الإنترنت لا تشجعني على العمل من خلالها & 2 \\
\hline 39.01 & 0.89 & 2.28 & 324 & لا أجيد استخدام الحاسوب للوصول إلى الخدمات الإكترونية & 3 \\
\hline 31.43 & 0.82 & 2.62 & & لمعوقات الإدارية & 4 \\
\hline
\end{tabular}

الجدول من إعداد الباحثة بناء على مخرجات التحليل الإحصائي

يتضح من الجدول السابق ما يلي:

هذا المنغير (88) مفردة؛ بنسبة (27.16)، وعدد غير الموافقين 1- بلغت قيمة المنوسط الحسابي لمتغير مدى صعوبة التعامل (181) مفردة؛ بنسبة (55.86)، وهذا يدل على ميل إجابات مع البوابات الإكترونية الحكومية (2.70)، وهذا بعني أنها تقع في لئي

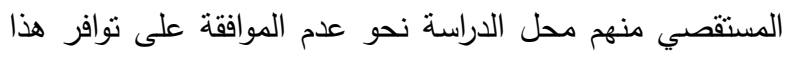

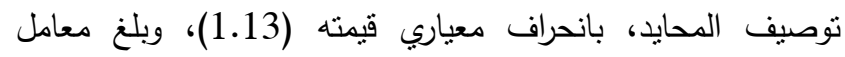
الاختلاف (41.78\%)، وهذا بعني وجود اختلاف واضح جداً بين المتغير. ب. التحليل الوصفي (المتوسطات) للمتغير المستقل (المعوقات (القانونية) آراء العينة محل الدراسة حول هذا المتغير ، ويتبين من الجدول التالي

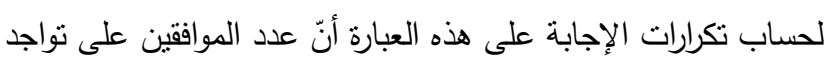

جدول رقم (14): التحليل الوصفي (المتوسطات) للمتغير الفرعي (المعوقات القانونبة)

\begin{tabular}{|c|c|c|c|c|c|}
\hline $\begin{array}{c}\text { معامل الاختلاف } \\
\text { \% }\end{array}$ & الانعراف & الحسابي & العينة & العبارة & s \\
\hline 22.91 & 0.86 & 3.77 & 324 & لا أعلم ما هي الحدود القانونية للعمل من خلال الخدمات الإككترونية، منل التوقيع والدفع & 1 \\
\hline 21.95 & 0.86 & 3.92 & 324 & أخشى من انخفاض مستوى الأمن والسرية في الخدمات الإلكترونية & 2 \\
\hline 19.75 & 0.78 & 3.93 & & المتغير الكلي للمعوقات القانونية & 3 \\
\hline
\end{tabular}

الجدول من إعداد الباحثة بناء على مخرجات التحليل الإحصائي

والدفع (3.77)، وهذا يعني أنها تقع في توصيف الموافقة، بانحراف معياري قيمته (0.86)، وبلغ معامل الاختلاف (22.91\%)، وهذا بعني وجود اختلاف واضح بين آراء العينة محل الدراسة حول هذا المتغير. يتضح من الجدول السابق ما يلي: 1- بلغت قيمة المتوسط الحسابي لمتغير عدم العلم بالحدود

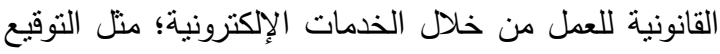


بانحراف معياري قيمته (0.78)، وبلغ معامل الاختلاف (19.75\%)، وهذا يعني وجود اختلاف محدود بين آراء العينة محل الدراسة حول هذا المتغير. 5. المتغير التابع : الفائدة المدركة ورضا المستخدمين أ) التحليل الوصفي (المتوسطات) للمتغير التابع (الفائدة

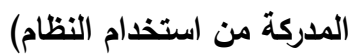

2-بلغت قيمة المنوسط الحسابي لمتغير الخوف من انخفاض مستوى الأمن والسرية في الخدمات الإلكترونية (3.92)، وهذا يعني أنها تقع في توصيف الموافقة، بانحراف معياري قيمته (0.86)، وبلغ معامل الاختلاف (21.95\%)، وهذا فئا فئاس يعني وجود اختلاف واضح بين آراء العينة محل الدراسة

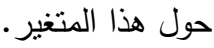

3-بلغت قيمة المتوسط الحسابي للمتغير الكلي للمعوقات القانونية (3.93)، وهذا يعني أنها تقع في توصيف الموافقة،

جدول رقم (15): التحليل الوصفي (المتوسطات) للمتغير الفرعي (الفائدة المدركة من استخدام النظام)

\begin{tabular}{|c|c|c|c|c|c|}
\hline الاختلاف & الانحراف & الحسابي & 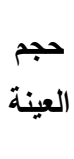 & 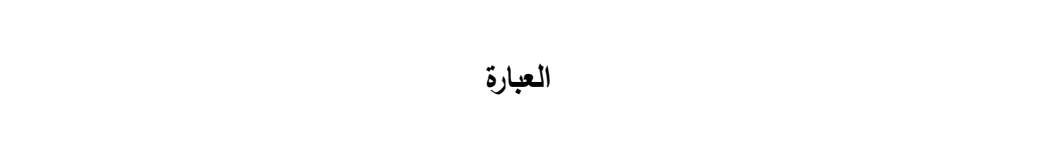 & b \\
\hline 16.06 & 0.70 & 4.35 & 324 & يخفف استخدام تكنولوجيا المعلومات في الإدارات الرسمية نفقات المعاملات فيها & 1 \\
\hline 14.06 & 0.62 & 4.44 & 324 & يؤدي استخدام تكنولوجيا المعلومات في الإدارات الرسمية إلى تحسين نوع الخدمات الدقدمة إلى & 2 \\
\hline 14.84 & 0.66 & 4.42 & 324 & من خلال الخدمات الإككترونية لن تضطر للذهاب للاوائر الحكومية & 3 \\
\hline 16.13 & 0.72 & 4.44 & 324 & تقديم الخدمات الإككترونية سيقلل الازدحام في الطرقات & 4 \\
\hline 17.89 & 0.78 & 4.35 & 324 & تقديم الخدمات الإلكترونية سيقلل نسبة التلوث & 5 \\
\hline 16.28 & 0.72 & 4.40 & 324 & الحصول على الخدمات الإلكترونية يتميز بالسرعة والدقة والثفافية & 6 \\
\hline \multicolumn{3}{|c|}{13.43} & 0.60 & المتغير الكلي للفائدة المدركة من استخدام النظام & 7 \\
\hline
\end{tabular}

قيمته (0.66)، وبلغ معامل الاختلاف (14.84\%)، وهذا يعني يتضح من الجدول السابق ما يلي:

وجود اختلاف محدود بين آراء العينة محل الدراسة حول هذا لآنا

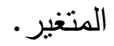

4. بلغت قيمة المتوسط الحسابي لمتغير تقليل تقديم الخدمات الإلكترونية للازدحام في الطرقات (4.44)، وهذا يعني أنها تقع في توصيف الموافقة بشدة، بانحراف معياري قيمته

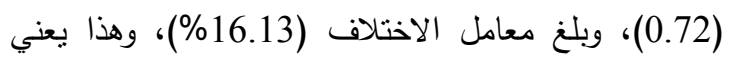
وجود اختلاف محدود بين آراء العينة محل الدراسة حول هذا

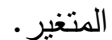
5. بلغت قيمة المتوسط الحسابي لمتغير تقليل تقديم الخدمات

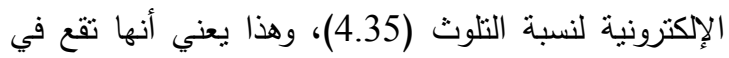
توصيف الموافقة بثدة، بانحراف معياري قيمته (0.78)،

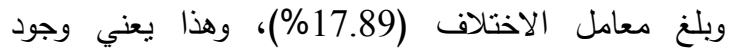

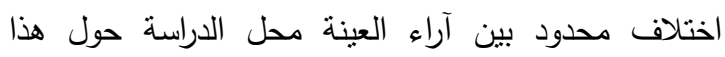

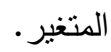

1. بلغت قيمة المتوسط الحسابي لمتغير تخفيف استخدام تكنولوجيا

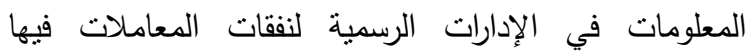
(4.35)، وهذا يعني أنها تقع في توصيف الموافقة بشدة، بانحراف معياري قيمته (0.70)، وبلغ معامل الاختلاف (16.06\%)، وهذا بعني وجود اختلاف محدود بين آراء العينة محل الدراسة حول هذا المتغير. 2. بلغت قيمة المتوسط الحسابي لمتغير استخدام تكنولوجيا

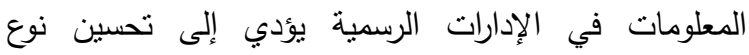

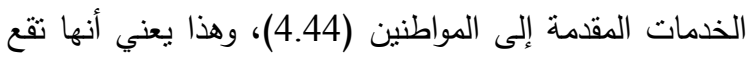

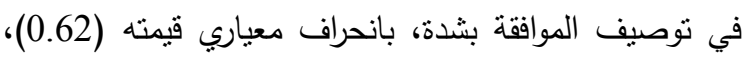
وبلغ معامل الاختلاف (14.06\%)، وهذا يعني وجود اختلاف محدود بين آراء العينة محل الدراسة حول هذا المتغير . 3. بلغت قيمة المتوسط الحسابي لمتغير عدم الاضطرار للذهاب للاوائر الحكومية من خلال الخدمات الإكترونية (4.42)، وهذا يعني أنها نقع في توصيف الموافقة بثدة، بانحراف معياري 
1-بلغت قيمة المتوسط الحسابي لمتغير نوفير الخدمات الإلكترونية للكثير من الوقت (4.51)، وهذا يعني أنها تقع في توصيف المونير الموافقة

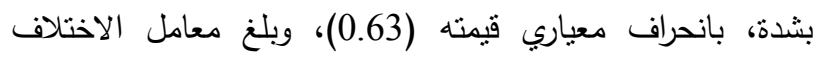
(13.90\%)، وهذا يعني وجود اختلاف محدود بين آراء العينة محل

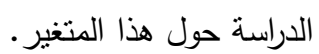
2- بلغت قيمة المنوسط الحسابي لمتغير الثعور بالرضا عما تقدمه الخدمات الالكترونية (2.87)، وهذا بعني أنها نقع في توصيف المحايدة، بانحراف معياري قيمته (1.03)، وبلغ معامل الاختلاف

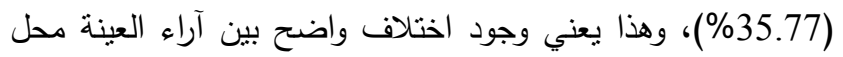
الدراسة حول هذا المتغير، ويتبين من الجدول التالي لحساب تكرارات

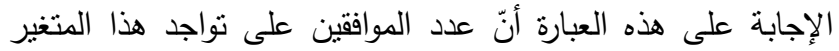
(100) مفردة؛ بنسبة (30.86)، وعدد غير الموافقين (162) مفردة؛ بنسبة (50.00)، وهذا يدلُ على ميل إجابات المستقصي منهم محل الدراسة نحو عدم الموافقة على توافر هذا المتغير .
6. بلغت قيمة المتوسط الحسابي لمتغير الحصول على الخدمات الإلكترونية يتميز بالسرعة والدقة والثفافية (4.40)، وهذا يعني أنها تقع في توصيف الموافقة بشدة، بندئ

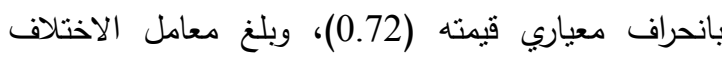
(16.28\%)، وهذا يعني وجود اختلاف محدود بين آراء العينة محل الدراسة حول هذا المتغير. 7. بلغت قيمة المتوسط الحسابي للمتغير الكلي للفائدة المدركة

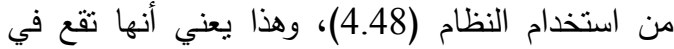
توصيف الموافقة بشدة، بانحراف معياري قيمته (0.60)،

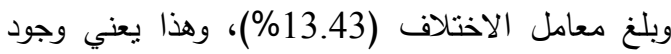
اختلاف محدود بين آراء العينة محل الدراسة حول هذا

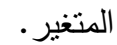

ب) التحليل الوصفي (المتوسطات) للمتغير التابع (رضا

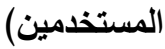
يوضح الجدول رقم (16) ما يلي:

جدول رقم (16): التحليل الوصفي (المنوسطات) للمتغير الفرعي (رضا المستخدمين)

\begin{tabular}{|c|c|c|c|c|c|}
\hline $\begin{array}{c}\text { معاملاف } \\
\text { \% }\end{array}$ & الانعراف & الحسابي & العينة & 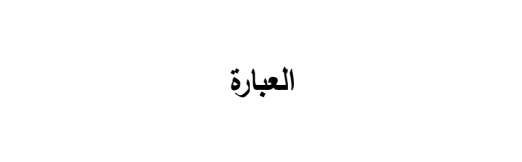 & r \\
\hline 13.90 & 0.63 & 4.51 & 324 & تُوفِّر الخدمات الإلكترونية الكثير من وقتلك & 1 \\
\hline 35.77 & 1.03 & 2.87 & 324 & أثعر برضا عما تقدمه الخدمات الإكترونية لي & 2 \\
\hline \multicolumn{2}{|c|}{18.38} & 0.72 & 3.93 & المتغير الكلي لرضا المستخدمين & 3 \\
\hline
\end{tabular}

* الجدول من إعداد الباحثة بناء على مخرجات التحليل الإحصائي خامساً: (ختبار الفرضيات

قامت الباحثة باستخدام أسلوب الاتحدار البسيط لاختبار الفروض الصفرية، وكانت نتائج اختبارات الفروض كما يلي:

جدول رقم (17) نتائج اختبار الرئيس (تطبيق الحكومة الإلكترونية ورضا المستخدمين والفائدة الدركة)

\begin{tabular}{|c|c|c|c|c|c|c|}
\hline \multicolumn{5}{|c|}{ الفائدة المدركة من استخدام النظام } & \multirow{2}{*}{ رضا المستخدمين } & \multirow{2}{*}{ الحكومة الإكترونية } \\
\hline $\begin{array}{c}\text { مستوى } \\
\text { sig }\end{array}$ & $\begin{array}{c}\text { F } \\
\text { المحسوية }\end{array}$ & $\begin{array}{c}\text { معامل } \\
\text { A } \\
\text { A }\end{array}$ & $\begin{array}{c}\text { الانحدار } \\
\text { معامل } \\
\text { الم }\end{array}$ & $\begin{array}{c}\text { معامل } \\
\mathbf{R}^{2}\end{array}$ & & \\
\hline 0.000 & 22.916 & 3.661 & 0.204 & 0.066 & \multicolumn{2}{|c|}{ حصول المستخدمين على الوسائل التكنولوجية } \\
\hline 0.000 & 25.763 & 3.700 & 0.214 & 0.074 & \multicolumn{2}{|c|}{ استخدام البرمجيات والثبكات } \\
\hline 0.478 & 0.504 & 4.422 & 0.021 & 0.002 & \multicolumn{2}{|c|}{ منطلبات نجاح الحكومة الإلكترونية (الثقافة الإلكترونية وآليات التوعية) } \\
\hline
\end{tabular}




\begin{tabular}{|c|c|c|c|c|c|}
\hline 0.000 & 27.802 & 3.703 & 0.221 & 0.079 & $($ مدى نجاح الخدمات الإكترونية (جودة الخدمات) \\
\hline 0.015 & 6.037 & 4.738 & 0.040 & 0.018 & المعوقات الإدارية \\
\hline 0.000 & 22.477 & 3.701 & 0.198 & 0.065 & المعوقات القانونية \\
\hline
\end{tabular}

* الجدول من إعداد الباحثة بناء على مخرجات التحليل الإحصائي

جدول رقم (18): نتائج اختبار الفرض الرئيس (تطبيق الحكومة الإكترونية ورضا المستخدمين والفائدة المدركة)

\begin{tabular}{|c|c|c|c|c|c|c|}
\hline \multicolumn{5}{|c|}{ رضا المستخدمين } & رضا المستخدمين & الحكومة الإلكترونية \\
\hline مستوى & $\begin{array}{c}\text { F } \\
\text { المحسوية }\end{array}$ & $\begin{array}{c}\text { معامل } \\
\text { A } \\
\text { A }\end{array}$ & $\begin{array}{c}\text { معامل } \\
\text { الانحدار } \\
\beta\end{array}$ & $\begin{array}{c}\text { معامل } \\
\text { التحديد } \\
\mathbf{R}^{2}\end{array}$ & & \\
\hline 0.000 & 37.310 & 2.700 & 0.306 & 0.104 & الوسائل التكنولوجية & حصو \\
\hline 0.000 & 46.35 & 2.709 & 0.335 & 0.126 & ت ت والشبكات & \\
\hline 0.000 & 45.659 & 3.326 & 0.224 & 0.124 & لثقافة الإلكترونية وآليات التوعية) & منطلبات نجاح الحن \\
\hline 0.000 & 58.697 & 2.630 & 0.369 & 0.154 & رونية (جودة الخدمات) & مدى نـ \\
\hline 0.311 & 1.028 & 3.796 & 0.049 & 0.003 & ل ل الإدارية & \\
\hline 0.903 & 0.015 & 3.901 & 0.006 & 0.000 & 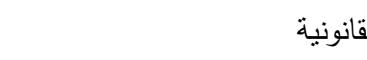 & \\
\hline
\end{tabular}

الجدول من إعداد الباحثة بناء على مخرجات التحليل الإحصائي

التكنولوجية والفائدة المدركة، مما يعني رفض الفرض العدمي وقبول الفرض البديل القائل بـ (وجود علاقة ذات دلالة إحصائية بين حصول المستخدمين على الوسائل التكنولوجية والفائدة المدركة من استخدام النظام من وجهة نظر المستخدمين للخدمات الإلكترونية بالمصالح الحكومية اللبنانية).

- عدم وجود علاقة ذات دلالة إحصائية بين حصول المستخدمين على الوسائل التكنولوجية والرضا من وجهة نظر المستخدمين للخدمات الإلكترونية بالمصالح الحكومية اللبنانية" ويتبين من نتائج الجدول السابق صحة الفرض الرئيسي، حيث كان مستوى الدلالة 0.000 وهي أقلّ من 0.005؛ مما بدل على

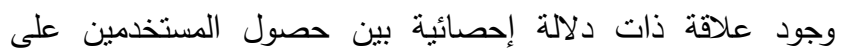
الوسائل التكنولوجية ورضا المستخدمين، مما بعني رفض الفرض العدمي وقبول الفرض البديل القائل بـ (وجود علاقة ذات دلالة إحصائية بين حصول المستخدمين على الوسائل التكنولوجية والرضا لمائ من وجهة نظر المستخدمين للخدمات الإكترونية بالمصالح الحكومية

اللبنانية).
- الفرض الرئيس الأول

( لا توجد علاقة ذات دلالة إحصائية بين تطبيق الحكومة الإلكترونية والفائدة المدركة، ورضا المستخدمين عن الخدمات إنهات الإكترونية بالمصالح الحكومية اللبنانية.

( $\mathrm{H}_{1}$ الإلكترونية والفائدة المدركة، ورضا المستخدمين عن الخدمات الإكترونية بالمصالح الحكومية اللبنانية.

\section{1. الفرض الفرعي الأول}

( لا توجد علاقة ذات دلالة إحصائية بين حصول

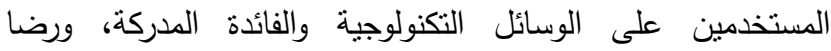
المستخدمين عن الخدمات الإلكترونية بالمصالح الحكومية اللبنانية. - عدم وجود علاقة ذات دلالة إحصائية بين حصول المستخدمين على الوسائل التكنولوجية والفائدة المدركة من وجهة نظر المستخدمين للخدمات الإلكترونية بالمصالح الحكومية اللبنانية ويتبين من نتائج الجدول السابق صحة الفرض الرئيسي، حيث كان مستوى الدلالة 0.000 وهي أقل من 0.05؛ مما يدل على وجود علاقة ذات دلالة إحصائية بين حصول المستخدمين على الوسائل 
إحصائية بين الثقافة الإكترونية وآليات التوعية والفائدة الددركة من استخدام النظام من وجهة نظر الستخذمين للخدمات الإكترونية بالمصالح الحكومية اللبنانية).

- عدم وجود علاقة ذات دلالة إحصائية بين النقافة

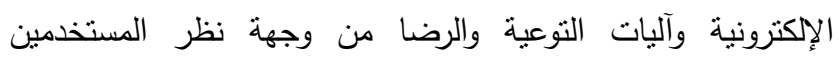
للخدمات الإلكترونية بالهصالح الحكومية اللبنانية"

ويتبين من نتائج الجدول السابق صحة الفرض الرئيسي، حيث

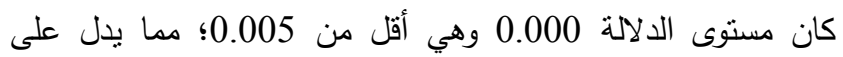

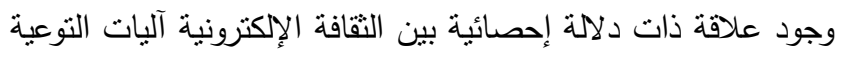
والرضا، مما بعني رفض الفرض العدمي وقبول الفرض البديل القائل بـ (وجود علاقة ذات دلالة إحصائية بين النقافة الإلكترونية وآليات التوعية والرضا من وجهة نظر الدستخدمين للخدمات الإلكترونية

بالمصالح الحكومية اللبنانية). - الفرض الرئيسي الثالث

( لا توجد علاقة ذات دلالة إحصائية بين مدى نجاح الخدمات الإلكترونية (جودة الخدمات الإلكترونية) والرضا والفائدة المدركة من استخدام النظام من وجهة نظر السستخدمين للخدمات الإلكترونية بالمصالح الحكومية اللبنانية" النغل - عدم وجود علاقة ذات دلالة إحصائية بين جودة الخدمات

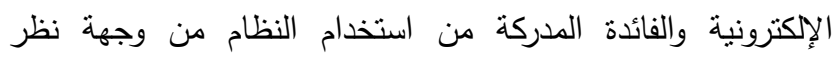
المستخدمين للخدمات الإلكترونية بالمصالح الحكومية اللبنانية ويتنين من نتائج الجدول السابق صحة الفرض الرئيسي، حيث

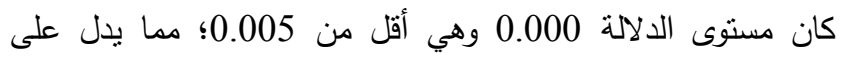
وجود علاقة ذات دلالة إحصائية بين جودة الخدمات الإلكترونية والفائدة الددركة من استخدام النظام، مما بعني رفض الفرض العدمي داني وقبول الفرض البديل القائل بـ (وجود علاقة ذات دلالة إحصائية بين

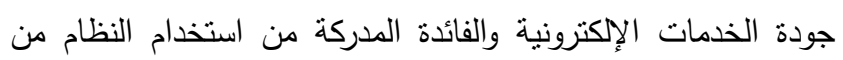

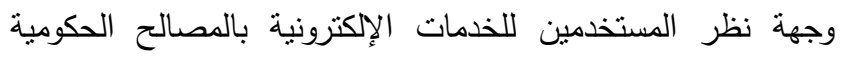
اللبنانية).

- عدم وجود علاقة ذات دلالة إحصائية بين جودة الخدمات الإلكترونية والرضا من وجهة نظر المستخدمين للخدمات الإكترونية

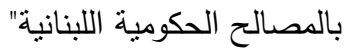

ويتبين من نتائج الجدول السابق صحة الفرض الرئيسي، حيث

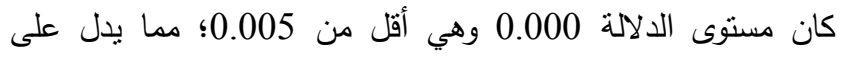
وجود علاقة ذات دلالة إحصائية بين جودة الخدمات الإلكترونية

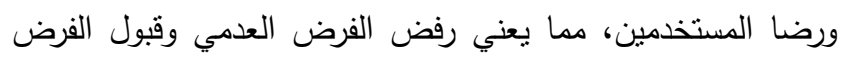
البديل القائل بـ (وجود علاقة ذات دلالة إحصائية بين جودة الخدمات
2.الفرض القرعي الثاني

( لا توجد علاقة ذات دلالة إحصائية بين استخدام

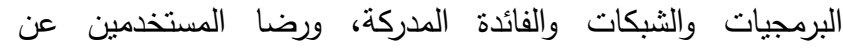
الخدمات الإلكترونية بالمصالح الحكومية اللبنانية.

- عدم وجود علاقة ذات دلالة إحصائية بين استخدام البرمجيات والثبكات والفائدة المدركة من استخدام النظام من وجهة

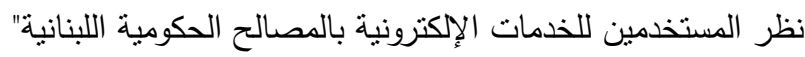
ويتبين من نتائج الجدول السابق صحة الفرض الرئيسي، حيث كان مستوى الدلالة 0.000 وهي أقل من 0.05؛ مما يدل على وجود علاقة ذات دلالة إحصائية بين استخدام البرمجيات والثبكات والفائدة المدركة، مما يعني رفض الفرض العدمي وقبول الفرض البديل القائل بـ (وجود علاقة ذات دلالة إحصائية بين استخدام البرمجيات والثبكات والفائدة المدركة من استخدام النظام من وجهة نظر المستخدمين للخدمات الإكترونية بالمصالح الحكومية اللبنانية). - عدم وجود علاقة ذات دلالة إحصائية بين استخدام البرمجيات والثبكات والرضا من وجهة نظر المستخدمين للخدمات الإلكترونية بالمصالح الحكومية اللبنانية"

ويتبين من نتائج الجدول السابق صحة الفرض الرئيسي، حيث

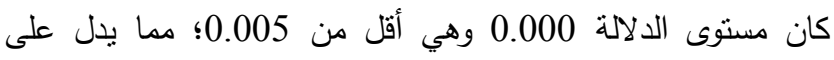
وجود علاقة ذات دلالة إحصائية بين استخدام البرمجيات والثبكات الثنات

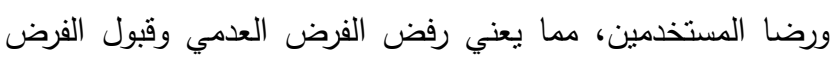
البديل القائل بـ (وجود علاقة ذات دلالة إحصائية بين استخدام البرمجيات والثبكات والرضا من وجهة نظر المستخدمين للخدمات الإلكترونية بالمصالح الحكومية اللبنانية).

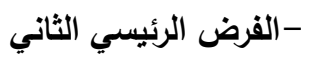

(Ho

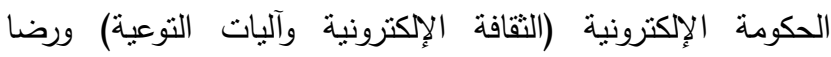
المستخدمين والفائدة المدركة من استخدام النظام من وجهة نظر الناله المستخدمين للخدمات الإلكترونية بالمصالح الحكومية اللبنانية" - عدم وجود علاقة ذات دلالة إحصائية بين الثقافة الإلكترونية وآليات التوعية والفائدة المدركة من استخدام النظام من

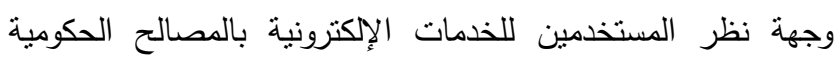
اللبنانية"

ويتبين من نتائج الجدول السابق صحة الفرض العدمي، حيث

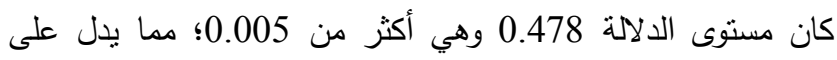
عدم وجود علاقة ذات دلالة إحصائية بين الثقافة الإككترونية وآليات

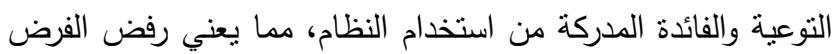
البديل وقبول الفرض العدمي القائل بـ (عدم وجود علاقة ذات دلالة الثان 
2.عدم وجود علاقة ذات دلالة إحصائية بين المعوقات

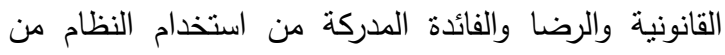
وجهة نظر المستخدمين للخدمات الإكترونية بالمصالح

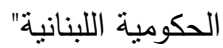

- عدم وجود علاقة ذات دلالة إحصائية بين المعوقات القانونية والفائدة المدركة من استخدام النظام من وجهة نظر دالئر

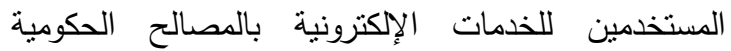

$$
\text { الللبنانية" }
$$

ويتبين من نتائج الجدول السابق صحة الفرض الرئيسي، حيث

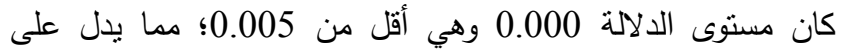
وجود علاقة ذات دلالة إحصائية بين المعوقات القانونية والفائدة المدركة، مما بعني رفض الفرض العدمي وقبول الفرض البديل القائل بـ (وجود علاقة ذات دلالة إحصائية بين المعوقات القانونية والفائدة المدركة من وجهة نظر المستخدمين للخدمات الإلكترونية بالمصالح

الحكومية اللبنانية).

- - عدم وجود علاقة ذات دلالة إحصائية بين المعوقات القانونية والرضا من وجهة نظر المستخدمين للخدمات الإلكترونية

$$
\text { بالمصالح الحكومية اللبنانية" }
$$

وينبين من نتائج الجدول السابق صحة الفرض العدم، حيث

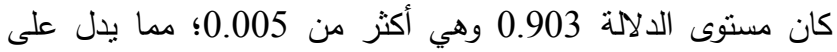
عدم وجود علاقة ذات دلالة إحصائية بين المعوقات القانونية والرضا،

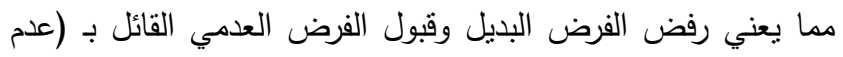

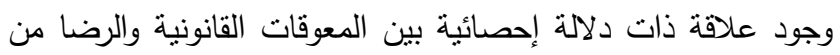
وجهة نظر المستخدمين للخدمات الإكترونية بالمصالح الحكومية

اللبنانية).

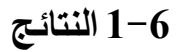

\section{6-1-1-6 نتائج التحليل الوصفي}

1- المتغير المستقل (تطبيق الحكومة الإلكترونية)

الإلكترونية والرضا من وجهة نظر المستخدمين للخدمات الإلكترونية بالمصالح الحكومية اللبنانية).

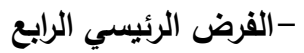

(Ho $1 \mathrm{H}_{0}$ الحكومة الإلكترونية (المعوقات الإدارية، والمعوقات القانونية) والرضا والفائدة المدركة من استخدام النظام من وجهة نظر المستخدمين

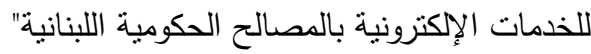
1. عدم وجود علاقة ذات دلالة إحصائية بين المعوقات الإدارية

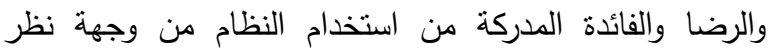

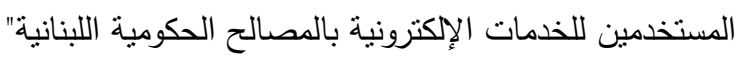
- عدم وجود علاقة ذات دلالة إحصائية بين المعوقات الإدارية

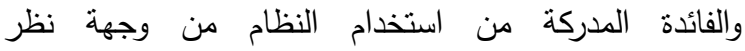
المستخدمين للخدمات الإلكترونية بالمصالح الحكومية اللبنانية" ويتبين من نتائج الجدول السابق صحة الفرض الرئيسي، حيث

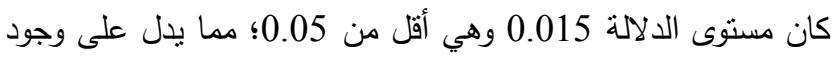
علاقة ذات دلالة إحصائية بين المعوقات الإدارية والفائدة الددركة، مما بعني رفض الفرض العدمي وقبول الفرض البديل القائل بـ (وجود

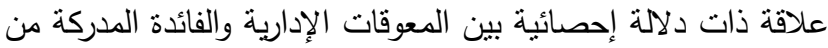

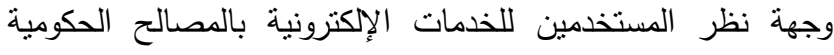
اللبنانية).

- عدم وجود علاقة ذات دلالة إحصائية بين المعوقات الإدارية والرضا من وجهة نظر الستخدمين للخدمات الإلكترونية

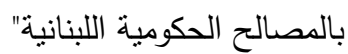
ويتبين من نتائج الجدول السابق صحة الفرض العدمي، حيث

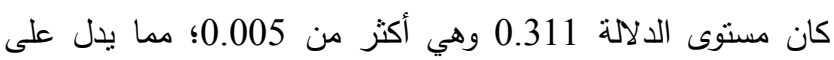
عدم وجود علاقة ذات دلالة إحصائية بين المعوقات الإدارية والرضا، مما يعني رفض الفرض البديل وقبول الفرض العدمي القائل بـ (عدم

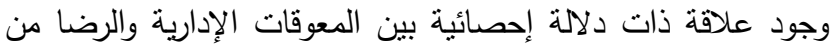

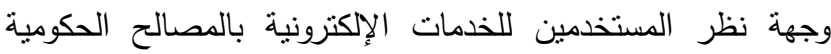

\begin{tabular}{|c|c|c|c|c|c|c|c|}
\hline \multicolumn{3}{|c|}{ استمارة العاملين } & \multicolumn{3}{|c|}{ استمارة المستخدمين } & \multirow[b]{2}{*}{ العبارة } & \\
\hline $\begin{array}{c}\text { معامل الاختلاف } \\
\text { \% }\end{array}$ & الانحراف & الحسابي & $\begin{array}{c}\text { الاختلاف معامل \% } \\
\text { \% }\end{array}$ & الانحراف & العسابي & & \\
\hline 19.68 & 0.77 & 3.90 & 20.45 & 0.76 & 3.74 & الحكومة الإلكترونية & 1 \\
\hline
\end{tabular}
اللبنانية).

جدول رقم (6-1): نتائج التحليل الوصفي للمتغير المستقل 


\begin{tabular}{|c|c|c|c|c|c|c|c|}
\hline 13.80 & 0.54 & 3.90 & 42.42 & 1.13 & 2.67 & منطلبات نجاح الحكومة الإكترونية & 2 \\
\hline 16.61 & 0.62 & 3.76 & 21.87 & 0.77 & 3.52 & مدى نجاح الخدمات الإكترونية & 3 \\
\hline- & - & - & 18.71 & 0.59 & 3.17 & معوقات تطبيق الحكومة الإلكترونية & 4 \\
\hline 14.33 & 0.54 & 3.76 & 16.78 & 0.56 & 3.31 & المتغير الكلي لنطبيق الحكومة الإلكترونية & 5 \\
\hline
\end{tabular}

المنوسط الحسابي لنفس المتغير ولكن بالنسبة لآراء العاملين (3.76)؛ وهذا بعني أن تقع في توصيف الموافقة أيضاً،

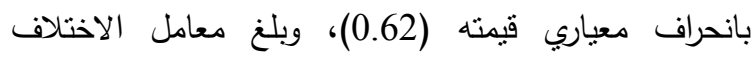
(16.61\%)، وهذا يعني وجود اختلاف محدود بين آراء العينة

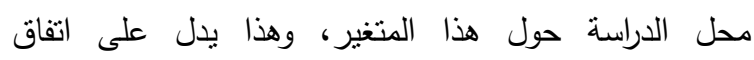

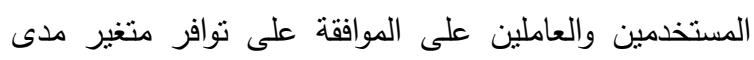

$$
\text { نجاح الخدمات الإلكترونية. }
$$

د. بلغت قيمة المتوسط الحسابي لمتغير معوقات نطبيق الحكومة

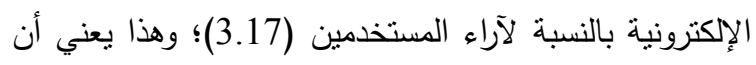
تقع في توصيف المحايد، بانحراف معياري قيمته (0.59)، وبلغ معامل الاختلاف (18.71\%)، وهذا يعني وجود اختلاف فئس محدود بين آراء العينة محل الدراسة حول هذا المتغير، وهذا وهاف يدل على حيادية رأي المستخدمين على نوافر متغير معوقات التهل

$$
\text { تطبيق الحكومة الإلكترونية. }
$$

هـ بلغت قيمة المتوسط الحسابي للمتغير الكلي لنطبيق الحكومة

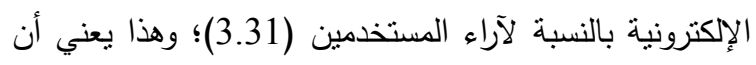

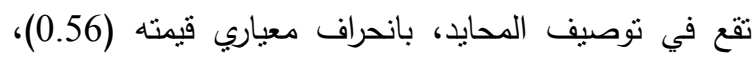

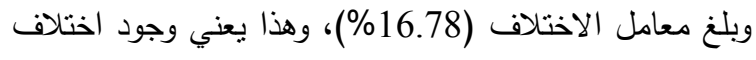

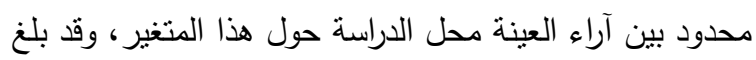

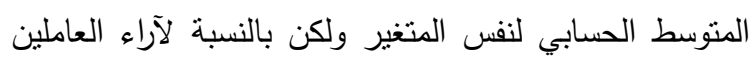

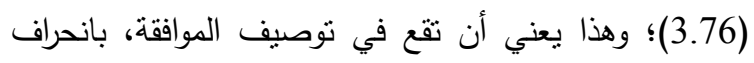

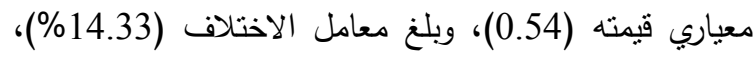

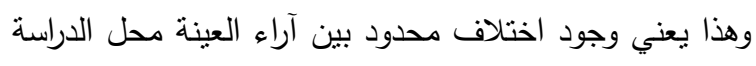

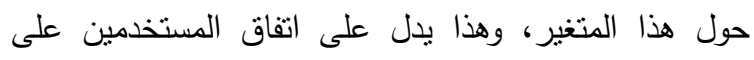

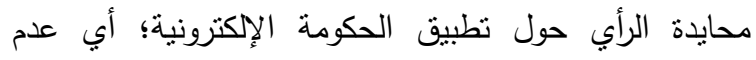

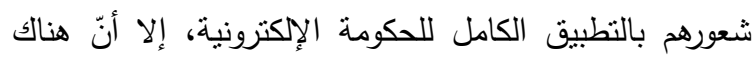
اتفاقاً بين العاملين على وجود تطبيق للحكومة الإكترونية.

$$
\text { 2. المتغير التابع (الأداء الإداري) }
$$

* الجدول من إعداد الباحثة بناء على مخرجات التحليل الإحصائي

$$
\text { يتضح من الجدول السابق ما يلي: }
$$

أ. بلغت قيمة المتوسط الحسابي لهتغير الحكومة الإكترونية بالنسبة لآراء المستخدمين (3.74)؛ وهذا بعني أنّها تقع في الإني توصيف الموافقة، بانحراف معياري قيمته (0.76)، وبلغ معامل الاختلاف (20.45\%)، وهذا يعني وجود اختلاف واضح بين الرافين

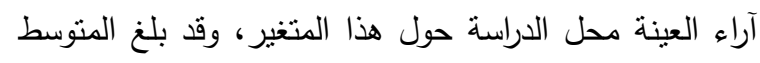
الحسابي لنفس المتغير ولكن بالنسبة لآراء العاملين (3.90)؛

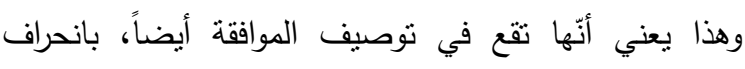

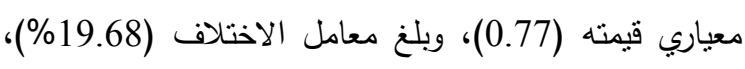
وهذا يعني وجود اختلاف محدود بين آراء العينة محل الدراسة الألة حول هذا المتغير، وهذا يدل على اتفاق المستخدمين والعاملين على الموافقة على توافر متغير الحكومة الإلكترونية. ب. بلغت قيمة المنتسط الحسابي لمتغير منطلبات نجاح

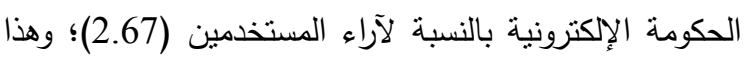
يعني أن نقع في توصيف المحايد، بانحراف معياري قيمته

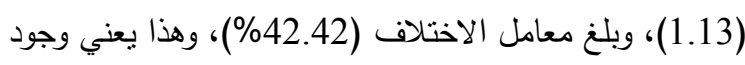

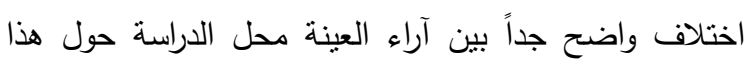

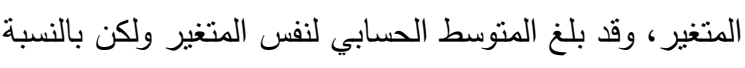

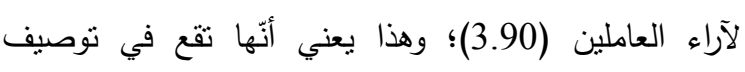

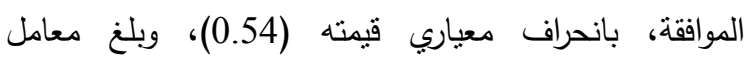
الاختلاف (13.80\%)، وهذا يعني وجود اختلاف محدود بين

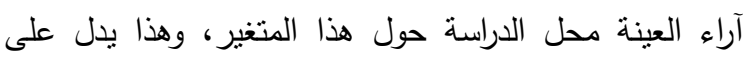

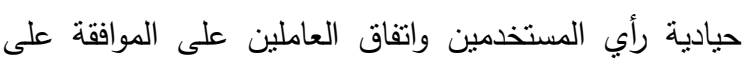
توافر متغير منطلبات نجاح الحكومة الإلكترونية. ج. بلغت قيمة المنوسط الحسابي لمتغير مدى نجاح الخدمات

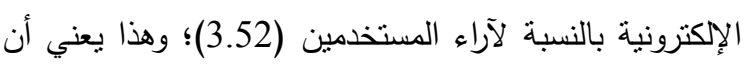

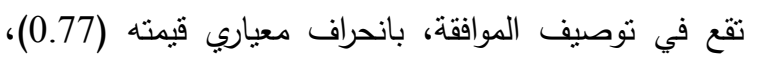

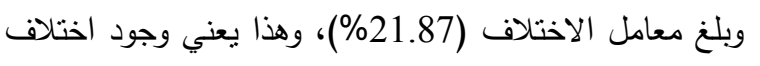

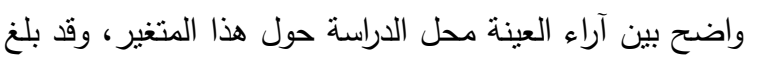


جدول رقم (6-2): نتائج التحليل الوصفي للمتغير التنابع

\begin{tabular}{|c|c|c|c|c|c|c|c|}
\hline \multicolumn{3}{|c|}{ استمارة العاملين } & \multicolumn{3}{|c|}{ استمارة المستخدمين } & \multirow[t]{2}{*}{ 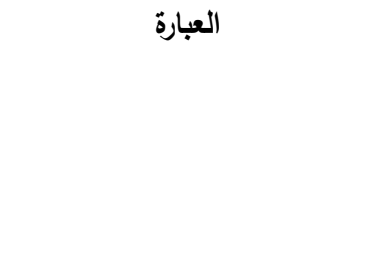 } & \multirow[t]{2}{*}{ b } \\
\hline $\begin{array}{c}\text { معامل الاختلف } \\
\text { \% }\end{array}$ & الانعراف & الحسابي & $\begin{array}{c}\text { معامل الاخف } \\
\text { \% }\end{array}$ & الانعراف & الحسابي & & \\
\hline 18.49 & 0.67 & 3.62 & 14.04 & 0.64 & 4.57 & الفساد الإداري & 1 \\
\hline 17.95 & 0.66 & 3.67 & 17.35 & 0.69 & 3.96 & تطوير الأداء الإداري & 2 \\
\hline 10.77 & 0.50 & 4.62 & 13.43 & 0.60 & 4.48 & الفائدة الددركة من استخدام النظام & 3 \\
\hline 16.53 & 0.67 & 4.05 & 18.38 & 0.72 & 3.93 & 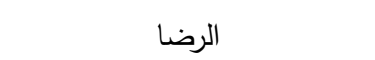 & 4 \\
\hline 16.61 & 0.62 & 3.76 & 13.43 & 0.58 & 4.32 & المتغير الكلي للأداء الإداري & 5 \\
\hline
\end{tabular}

* الجدول من إعداد الباحثة بناء على مخرجات التحليل الإحصائي

الاهتمام بالثقافة الإكترونية وتوعية الجمهور المستقيد من الخدمات الحكومية الإلكترونية بأهميتها، وكذلك زيادة وسائل التوعية الخاصة بنشر مزايا التطبيقات الإكترونية ومزايا الحكومة الإلكترونية. ضرورة الاستخدام الجيد للبرمجيات والشبكات؛ من أجل سهولة الانتشار والتعامل السهل بين المصالح الحكومية وجمهور المستخدمين والمستقيدين من خدماتها. وتوصي الدراسة بضرورة تغطية الخدمات الإلكترونية لجميع مناحي العمل في هذه الوزارات، وتطبيق الحكومة الإلكترونية

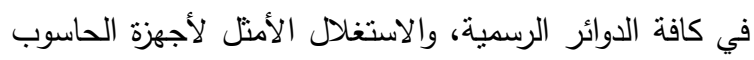

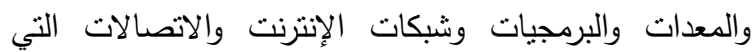
تمنلكها الوزارات، لتقديم خدمات إلكترونية منطورة وتحقيق الاستفادة القصوى منها. Advanced Services الوصول إلى تقديم الخدمات المتطورة وعدم الاكتفاء بتقديم خدمات صماء Damp Services، للوصول إلى النطبيق الكامل للحكومة الإلكترونية حيث يمنل الموقع الإلكتروني بيئة عمل داخلية حية تمثل فعلياً بيئة الجهاز الإداري مع القدرة على تلبية جميع طلبات المستفيدين من خلال هذا الموقع. حيث تبين أنّ الخدمة التي تقدمها الإدارات الرسمية تُعى بالخدمة الصماء Damp Service،

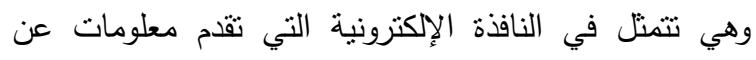
الخدمات والمعاملات التي ثنثها الجهة الحكومية للمواطن وليس هناك إمكانية للتفاعل مع المستفيد.
يتضح من الجدول السابق ما يلي: أ. بلغت قيمة المتوسط الحسابي لمتغير الفائدة المدركة من استخدام النظام بالنسبة لآراء المستخدين (4.48)؛ وهذا يعني أن تقع في نوصيف الموافقة بشدة، بانحراف معياري

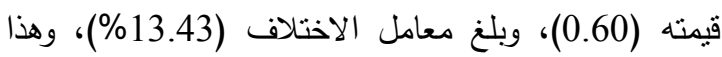
يعني وجود اختلاف محدود بين آراء العينة محل الدراسة حول هذا المتغير، وهذا بدل على أنّ هناك فائدةً مدركة من الني

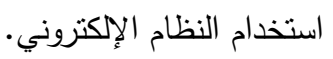

ب. بلغت قيمة المتوسط الحسابي لمتغير الرضا بالنسبة لآراء

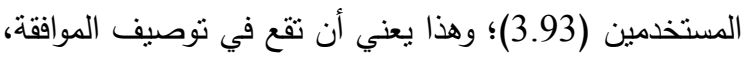

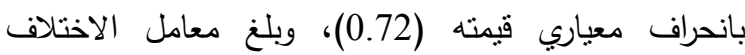
(18.38\%)، وهذا يعني وجود اختلاف محدود بين آراء العينة محل الدراسة حول هذا المتغير، وهذا يدل على اتفاق

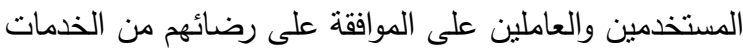

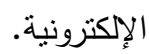

2-1-6 مناقثة النتائج

تتفق الدراسة مع دراسة (Delone)8 ونستتنج وجود علاقة

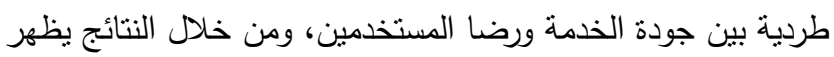

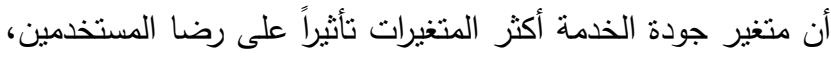

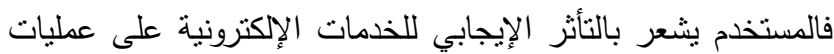
الإدارة العامة. كما أنّ هذه الدراسة تتفق مع دراسة (Delone( ومنها لإنها

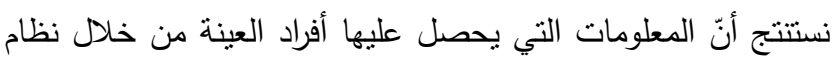
الخدمات الإلكترونية ملائمة لطبيعة عمل الموظف، وتتمتع بجودة المعلومات، وهو ما يؤدي إلى رضا المستخدم عنها بزيادة جودتها. 
Case study: Rasht municipality", Master Thesis, Lulea University of Technology, Sweden, (2011).

13. Murad, Abdel Fattah, The electronic and digital government, Alexandria, (2005).

14. Nunnly,Jane, Psychometric Theory (2nd, Ed.) New York: Mc Graw Hill, (1995)

15. Roomi, Ismail Musa\& Salah Ali Mahmoud, The Reality of the Effectiveness of Information Systems from the Viewpoint of Decision Makers at Al-Quds Open University, Palestine, Journal of Al-Quds Open University for Research and Studies, Issue (27), 2012.

16. Sandh,Haroon Shahzad\&Waqas Younas, EGovernment Services In Pakistan,Lulea University of Technology - Department of Business Administration and Social Science, (2007).

17. Zuhair, Qabbs\&Jaafar Abdul Karim, TheImpact of Electronic Management on Total Quality Management: A Case Study in the Information Technology Department of the Ministry of Science and Technology Baghdad, (Iraq: Journal of Management and Economics, Al-Mustansiri University), Issue (100), 2014.

18. Zikmund,William, Business Research Methods (6th ed.), New York: Harcourt College Publishers, (2000)

19. Zviran, Moshe,ChananGlezer,\& Itay Avni, User satisfaction from commercial web sites: The effect of design and use, Journal of Information and Management, Vol. 43, Issue 2,2006
ل من الواضح أنّ حجم الإقبال على خدمات الحكومة الإلكترونية

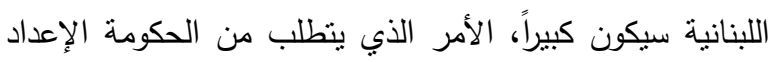

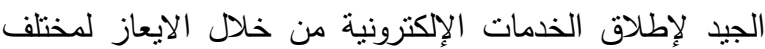

$$
\text { الوزارات والمؤسسات الحكومية بذلك. }
$$

\section{References}

1. Adwan,Iyad Khaled, The Extent of Citizens' Acceptance to Access Services through EGovernment - Gaza Strip Case Study, Unpublished Master Thesis, (Palestine: The Islamic University), (2007).

2. Al-Ghouti, Ibrahim, Requirements for the Success of the E-Government Project from the Point of View of Senior Management in Palestinian Ministries, Unpublished Master Thesis , (Gaza: The Islamic University), (2006.(

3. Al-Ghunaim, Abdul Aziz, the e government,Informatics Journal, No. 8, (2005).

4. Ali Ibrahim, Mustafa\& Abdul Hussein Ali Mustafa, The Impact of E-Government Implementation on the Level of Tax Compliance in Iraq, Iraq: Al-Muthanna Journal for Administrative and Economic Sciences, Issue (3), Issue (5), Iraq, (2012).

5. Ashmawy, Abdel Halim, Jalal, Salah, \& Sadiq Muhammad, Biostatistics and Experimental Design, Cairo: Academic Library, (2008.(

6. Awang, Kader, Measuring information system performance in public sector: A case study in Pahang State Education Department,Master thesis, university of Malaya, Malaysia, (2009)

7. Churchil,Gillbert, Marketing Research: Methodological Foundations. (5th, Ed.) New York, (1991).

8. Delone,William, \& Mclean Ephraim, The Delone and Mclean model of information system success: A ten year update, Journal of Management Information Systems, Vol. 19, $\mathrm{N}: 4$, pp. 9-30, (2003).

9. Tull, Giles, \& Hawkins, Del, 1993. "Marketing Research Measurement and Methods," New York, McMillan Publishing Company.

10. Fakeeh, Khalid, The E-governance (E-GOV) information management models, International Journal of Applied Systems, Foundation of Computer Science, Vol. 11,No:1, New York USA, (2016).

11. Khair, Muhammad, Methods of statistical analysis using SPSS software, Algeria: House of Serenity, (2005).

12. Mobahi, Hadis, The Adoption of Egovernment Services by Employees in Iran 